\title{
LAS PINTURAS DE LA SALA CAPITULAR DE LA CATEDRAL DE TOLEDO: APORTACIÓN AL ESTUDIO DE LA CONCEPCIÓN DEL ESPACIO
}

\author{
POR \\ OLGA MARÍN CRUZADO \\ Departamento de Historia del Arte del CSIC
}

\begin{abstract}
This article is an study about the trataiment of perspective of the frescoes in the Sala Capitular of the Toledan Cathedral, Juan de Boprgoña's documented work. The conclusion is an important Flemish formation in the Juan de Borgoña's career.
\end{abstract}

Juan de Borgoña fue el encargado de embellecer los muros de la sala capitular de la catedral de Toledo. Hacer referencia a una obra conservada y de enorme trascendencia para la historia del arte español, obliga a empezar repasando la documentación recopilada por Pérez Sedano y Zarco del Valle, publicada posteriormente en 1914 y 1916 '.

Juan de Borgoña aparece relacionado con la sala capitular a partir del cinco de junio de 1508 al tasar la pintura del artesonado; el nueve de octubre se le paga por el viaje para informar al cardenal Cisneros de la trayectoria de su empresa. Comienza a recibir pagos por la pintura de los muros de la sala capitular a partir del veintiséis de septiembre de 1509; al día siguiente, aparece como tasador de la azotea terminada por Luis de Medina, y el veintiséis de octubre vuelve a ser pagado por lo que tiene que pintar, manteniéndose los pagos regularmente al año siguiente, en enero, marzo, mayo, septiembre, y en 1511, en enero, febrero, marzo, junio, septiembre, y por último, en noviembre. Mientras tanto, vuelve a aparecer como tasador de la pintura del zaguán pagada a Luis de Medina el veinticinco de noviembre de 1510.

Aparte de estas publicaciones documentales sobre las pinturas de la sala capitular de la catedral de Toledo realizadas por Juan de Borgoña, nos encontramos abundantes referencias a ellas. La primera la realiza Ponz, nos dice que tiene entendido que habían sido realizadas por Pedro Berruguete, del que duda su existencia, pero lo adula al equipararlo en valía a Perugi$n^{2}$. Ceán recoge todas las noticias documentales recopiladas por Pérez Sedano, y la atribu-

1 F. PÉrez Sedano, «Notas del Archivo de la Catedral de Toledo redactadas sistemáticamente en el siglo xviII» en Datos documentales inéditos para la Historia del Arte Español, I, Madrid, 1914, pp. 33-34, 37, 38, 126 y 127. M. R. ZARCO DEL VALLE, «Documentos de la catedral de Toledo: colección formada en los años 1869-74 y donada al Centro en 1914», I, en Datos documentales para la Historia del Arte español, II, Madrid, 1916, pp. 106, 109, 110, 111, 112 y 114.

2 A. Ponz, Viage de España, I, 1. ${ }^{\mathrm{a}}$ ed. 1772, 3. ${ }^{\mathrm{a}}$ ed., Madrid, 1787, pp. 91-94. 
ción a Pedro Berruguete de Ponz, añade el nombre de Borgoña en la conclusión del trabajo y como autor de los retratos de los arzobispos al fresco y al óleo ${ }^{3}$. Amador de los Ríos habla del estilo de Juan de Borgoña al referirse a los retratos de los prelados, enuncia los temas tratados en las historias con algún error, confunde la Presentación de la Virgen en el templo con sus Desposorios, y añade en las atribuciones, aparte del nombre de Pedro Berruguete, el de Vicente Macip, pero afirma fueron pintadas por Juan de Borgoña; entre todas destaca la Asunción, por su composición «bien pensada y dispuesta», sus figuras «gallardas» y expresivas, y los paños «plegados con nobleza y abundancia» ${ }^{4}$. Parro describe minuciosamente todo lo referente a la sala capitular, recoge las noticias aportadas por sus predecesores, pero ya no existe ni siquiera la duda sobre el autor de los frescos, «el tan conocido artista Juan de Borgoña», del que destaca las mismas cualidades y defectos que veía Amador de los Ríos ${ }^{5}$. Quadrado, en sus viajes por Castilla, se ve sorprendido por la sala capitular de la catedral de Toledo, en sus pinturas al fresco «se elevó Borgoña á cierto vigor y grandiosidad apenas conocida en su tiempo», repite la confusión de Amador de los Ríos ${ }^{6}$. Otro viajero de estas últimas décadas del siglo xIx, el conde de Cedillo, encuentra en la sala capitular «lo mejor y más perfecto de su época», describe todo lo que ve, y de las pinturas, cada escena, para concluir adulando al maestro, Juan de Borgoña, en su estilo pictórico y su manera de componer, se fija en los fondos, paisajes y edificios ${ }^{7}$. En la Sociedad Española de Excursiones no podía faltar la visita a Toledo y a la sala capitular de su catedral, insisten en ver los Desposorios en vez de la Presentación en el templo de la Virgen, y también, en repetir las adulaciones iniciadas por Ponz ${ }^{8}$. Bertaux insiste en la influencia italiana de Juan de Borgoña en la sala capitular, una de las muestras de ese italianismo es el tratamiento de la perspectiva ${ }^{9}$. Mayer continúa el camino de las posibles influencias italianas en Juan de Borgoña, fundamentalmente toscanas de Ghirlandaio y lombardas de Borgognone, aparece como «hombre muy activo, muy cuidadoso, sobre todo en el dibujo y la perspectiva» ${ }^{10}$. Va a ser de la pluma de otro extranjero de donde provengan las novedades referidas a Juan de Borgoña y la sala capitular, Post recoge todos los datos documentales recopilados por Sedano y Zarco del Valle, se extiende en la distribución de las pinturas, razona sobre la parte de las escenas narrativas y la de los retratos de los prelados, unificando ambos trabajos en el mismo contrato ${ }^{11}$. El autor americano se sirve de la descripción y análisis de la obra capital de Juan de Borgoña para perfilar su estilo a través de la búsqueda de antecedentes italianos, de nuevo, los toscanos de Ghirlandaio y los lombardos de Borgognone, a los que añade muchos otros, Piero de Cosimo, Filippino Lippi, Pinturicchio, Andrea del Castagno, Cosimo Rosselli, Melozzo da Forlì, Piero della Francesca, Signorelli y algunos más, influencias italianas también en las arquitecturas, y castellanas en el dorado. Post va a aportar

\footnotetext{
3 J. A. CEÁn Bermúdez, Diccionario histórico de los más ilustres profesores de las Bellas Artes en España, Madrid, 1800, ed. fac. 1965, I, pp. 164-165; III, pp. 45 y 103; IV, p. 322.

${ }^{4}$ J. AmAdor de Los Ríos, Toledo Pintoresca, ó descripción de sus más célebres monumentos, Madrid, 1845, pp. 73-75.

${ }^{5}$ S. R. PARro, Toledo en la mano, I, Toledo, 1857, pp. 628-645.

6 J. M. Quadrado y V. DE LA Fuente, «Toledo y Ciudad Real» en España, sus monumentos y artes su naturaleza e historia: Castilla la Nueva, III, 1. ${ }^{a}$ ed. 1850, Barcelona, 1886, pp. 221-224.

${ }^{7}$ C. DE Cedillo, Toledo: guía artístico-práctica, Toledo, 1890, pp. 415-422. Ídem, Catálogo monumental y artístico de la catedral de Toledo, intr. y notas de M. Revuelta Tubino, Madrid, 1991, pp. 193-195, donde hace referencia a la similitud con las pinturas italianas (p. 195).

${ }^{8}$ P. A. Berenguer, «La Sociedad Española de Excursiones en Toledo, I», Boletín de la Sociedad Española de Excursiones, $\mathrm{n}^{\circ} 5,1893$, pp. 47-48.

${ }^{9}$ É. BeRTAUX, «La Renaissance» en Histoire de l'Art: depuis les premiers temps crétiens jusqu'a nos jours, IV, París, 1911, p. 921.

10 A. L. MAYer, Historia de la Pintura española, 1. ${ }^{a}$ ed. 1928, 2. a ed., Madrid, 1942, pp. 184-188 (lo referente a Juan de Borgoña), en relación a la sala capitular no se añade nada en la edición de 1942, de lo recogido en este artículo únicamente es novedad en la segunda edición la influencia lombarda de Borgognone en las vírgenes de Juan de Borgoña.

11 Сн. R. Post, A History of Spanish Painting, IX(I), Cambridge, Massachusetts, 1947, pp. 166-168.
} 
novedades al fijarse en algunos detalles referentes a la composición de las historias religiosas de la sala capitular, su enmarque a través de una columnata y de un arquitrabe, conjunto que aparenta estar delante de las composiciones y formar parte de ellas, el desarrollo de las escenas en amplios interiores renacentistas como en los frescos del coro de santa María Novella de Ghirlandaio, la importancia de los entornos arquitectónicos y paisajísticos por encima de las figuras, y la preocupación por la perspectiva y la relación de los espacios concatenados ${ }^{12}$. Brans no va a tener en gran estima a Juan de Borgoña, pero no puede evitar postrarse ante las pinturas de la sala capitular «con escenas con grandes paisajes, dan profundidad a los muros» ${ }^{13}$. Similares palabras con respecto al espacio arquitectónico y paisajístico utiliza Lafuente Ferrari, y aunque compara los frescos del cabildo con los de santa María Novella y de Orvieto, al igual que Post, añade una influencia flamenca en la iconografía ${ }^{14}$.

La primera monografía sobre Juan de Borgoña aparece mediado el siglo xx de la mano de Diego Angulo ${ }^{15}$, a las influencias estilísticas italianas de Ghirlandaio, Borgognone, Perugino, Piero della Francesca, Melozzo da Forlì y los venecianos, añade la nórdica, con modelos de Gerard David, y la castellana de Pedro Berruguete, por la utilización del oro y las techumbres moriscas. Angulo atiende también a los amplios escenarios arquitectónicos de Juan de Borgoña, preocupado por la perspectiva y los efectos luminosos. Dedica a la sala capitular de la catedral de Toledo una minuciosa descripción, destacamos lo referente al espacio con la estructuración de los muros a través de unos vanos fingidos mediante columnas, «se transforman en alegre ámbito abierto, con hermosas vistas de bellas perspectivas arquitectónicas y dilatados paisajes» ${ }^{16}$, en cada una de las historias hace hincapié en la descripción de la arquitectura con recuerdos toscanos, venecianos, del norte de Italia, o en el caso de la Imposición de la casulla a san Ildefonso y en la Purificación, góticos, que más que recuerdos eran realidades hispanas, en la representación del paisaje de la Visitación, y de las escenas de la Pasión en el testero este, el recuerdo es flamenco al excluir todo referente arquitectónico y preocuparse más por la naturaleza (Gerard David, Roger van der Weyden), pero en las formas es italiano (Pinturicchio), la disposición escalonada aumenta y favorece la profundidad, pero no es únicamente el escenario y el espacio lo que preocupa a Borgoña, para Angulo lo más importante es la luz, sus distintos focos, los juegos con zonas luminosas y ensombrecidas.

Condorelli, bajo su punto de vista italiano y teniendo muy cerca los ejemplos que otros autores han puesto en paralelo a la obra de Juan de Borgoña, hace prevalecer la influencia romana, Antoniazzo Romano, y el influjo de Pedro Berruguete al llegar a España ${ }^{17}$, en la sala capitular de la catedral de Toledo encuentra un poso francoflamenco e influencias italianas del propio Antoniazzo y Melozzo da Forlì. Condorelli no excluye lo referente a la perspectiva y a la luz, siguiendo el camino abierto por Angulo, las considera muy importantes en la obra de Juan de Borgoña. Camón Aznar se mantiene en la línea de Post de encontrar en la obra de Juan de Borgoña una influencia más variopinta, pero fundamentalmente toscana, hace alusiones a los fondos arquitectónicos «de una complejidad de planos perspectivos» hacia la lejanía y la apertura paisajística, con «los problemas del claroscuro» ${ }^{18}$. Buendía añade la re-

\footnotetext{
12 Ídem, pp. 176-197.

13 J. V. L. Brans, Isabel la Católica y el arte Hispano-Flamenco, Madrid, 1952, pp. 134-137.

14 E. Lafuente Ferrari, Breve historia de la pintura española, I, 4. ${ }^{\mathrm{a}}$ ed., Madrid, 1953, pp. 169-171.

15 D. Angulo Íl̃Iguez, Juan de Borgoña, Madrid, 1954. Ídem, «Pintura del Renacimiento», Ars Hispaneae, XII, Madrid, 1955, pp. 112-127.

${ }_{16}$ Ídem, 1954, p. 14.

17 A. Condorelli, «Il problema di Juan de Borgoña», Commentari, XI, n 1, 1960, pp. 46-59. R. LongHI, Officina Ferrarese, Padua, 1934. Ídem, «Per Juan de Borgoña», Paragone, XVI, n 189, 1965, pp. 65-71, da también mayor importancia a la estancia en Roma de Juan de Borgoña.

18 J. CAmón Aznar, «La pintura española del siglo XVI», Summa Artis, XXIV, 1966, 6. a ed., Madrid, 1994, pp. 139-140.
} 
lación de Juan de Borgoña con Pedro Berruguete en Urbino, analiza los elementos arquitectónicos y los tres niveles visuales que él establece en «la escenografía arquitectónica, las figuras y el paisaje», por primera vez se habla de perspectiva lineal en la sala capitular, tomada de esquemas italianos ${ }^{19}$. Las aportaciones de Cruz Valdovinos son fundamentalmente documentales ${ }^{20}$, presta atención a la perspectiva y a la luz al describir el retablo de la iglesia parroquial de san Juan Bautista en Camarena (Toledo), menciona la lateralidad del foco de luz, los amplios escenarios arquitectónicos, el paisaje y la «perspectiva oblicua» en cuatro de las tablas, la mayor influencia en Juan de Borgoña para Cruz Valdovinos parece provenir de Roma. Checa destaca en Juan de Borgoña su «preocupación por la amplitud espacial y de los escenarios» al dominar la perspectiva «sin problemas» y el «sentido lumínico», para él «quizá sea Juan de Borgoña el maestro que con mayor conciencia utiliza la arquitectura pintada como medio de definir los amplios espacios clasicistas...», le sirve esta premisa para analizar tipológicamente las arquitecturas pintadas por Juan de Borgoña ${ }^{21}$. Marías va a ser el que estudie minuciosamente la perspectiva en Juan de Borgoña y la importancia que tiene su obra en la historia del arte español, por ser el precursor, sin antecedentes, de la utilización de una perspectiva monofocal, en composiciones simétricas, que pretenden sustituir la realidad en la que se encuentra el espectador, para pasar a formar parte del espacio pintado. Sin dar de lado a la vinculación de Juan de Borgoña con Ghirlandaio, no desestima las características nórdicas en su pintura, y a la vista de la antesala y la sala capitular, una estancia romana. Al analizar estas pinturas del cabildo toledano, Marías destaca, en contraposición a otras opiniones vistas más arriba, el protagonismo de la figura humana, «compañera del espectador», cuya presencia es escalonada y acompaña a la arquitectura en el sentido de profundidad de un espacio concebido autónomamente para cada escena, salvo en las tres de la Pasión, la luz proviene de diferentes focos o se unifica ${ }^{22}$. Ana Ávila en su artículo sobre perspectiva en el primer Renacimiento dedica una parte a la sala capitular, destaca la fusión entre lo real y lo ficticio y la concepción del espacio a partir de una línea de horizonte baja al tener en cuenta la situación de un espectador móvil, con puntos de fuga laterales ${ }^{23}$. Brown utiliza el supuesto segundo viaje a Italia de Juan de Borgoña centrado en Roma, siguiendo la tradición de Condorelli, para situar en esos momentos, entre los años 1505 y 1506, su italianización, «en especial en lo relacionado con su comprensión de la perspectiva», y mientras que en la proporción de las figuras continúa siendo un pintor nórdico, la influencia de Ghirlandaio prevalece. En Brown hay cierta confusión al relacionar los frescos de santa Maria Novella en Florencia con los de la antesala capitular, debe de estarse refiriendo a la Última Cena del refectorio de Ognissanti en Florencia, comparación sostenida por varios autores con anterioridad a Brown ${ }^{24}$, disminuye el número de escenas marianas en la sala capitular a ocho ${ }^{25}$, en estas pinturas se fija en los elementos arquitectónicos, fundamentalmente clasicistas, con un «magistral empleo de la perspectiva» de los espaciosos escenarios ${ }^{26}$.

\footnotetext{
19 R. BuendíA, «Tercera parte: Pintura» en El Renacimiento, (Historia del Arte Hispánico, III), Madrid, 1980, pp. 207-

20 J. M. CRuz Valdovinos, «Retablos inéditos de Juan de Borgoña», Archivo Español de Arte, LIII, n 209, 1980 , pp. $27-$

21 F. Checa Cremades, Pintura y escultura del Renacimiento en España, 1450-1600, Madrid, 1983, pp. 132, 141 y 160

${ }_{22}$ F. Marías Franco, El largo siglo XVI: los usos artísticos del Renacimiento español, Madrid, 1989, pp. $203-214$.

${ }^{23}$ A. Ávila, «La perspectiva en la pintura hispánica del primer Renacimiento», Archivo Español de Arte, LXIII, n 252 , 1990 , pp. 549-553 con 6 figs.

${ }^{24}$ El primero en hacer esta comparación fue Ch. R. Post, loc. cit. nota 11, p. 195.

${ }^{25}$ En la recopilación de lo referente a Juan de Borgoña realizada por P. MARTínez BuRgos con motivo de la exposición Reyes y mecenas, Toledo, 1992, pp. 533-534, comete el mismo error en el número de los temas tratados en la sala capitular, al igual que el antecedente de santa Maria Novella para la antesala capitular.

${ }^{26}$ J. Brown, La Edad de Oro de la pintura en España, Madrid, 1990, pp. 14-20.
} 210 56. 
Vamos a cerrar el paseo por la historiografía, fundamentalmente referida a la sala capitular, con el único artículo monográfico sobre las pinturas que allí realiza Juan de Borgoña ${ }^{27}$, el tema fundamental del artículo de Isabel Mateo se centra en la antesala capitular, a la que hemos hecho escasas referencias por no ser obra documentada de Juan de Borgoña ${ }^{28}$. El artículo de Mateo aclara la simbología de una decoración mural únicamente vegetal, como preludio al tema mariano desarrollado en el cabildo, hace referencia a «ventanales fingidos que dan a un jardín» cuando describe lo que se puede ver al acceder al pequeño recinto.

Ante una obra magistral nos hemos encontrado que casi está dicho todo, pero queremos intentar aportar una visión más amplia sobre el estudio de la perspectiva, el espacio y la luz en la sala capitular de la catedral de Toledo, con el fin de apoyar ciertas conclusiones sobre las influencias en la pintura de Juan de Borgoña.

Es obligado hacer una breve descripción de lo que un visitante se encuentra al traspasar el umbral del arco mixtilíneo que da acceso a la antesala capitular. Por problemas de espacio nos vemos obligados a remitir a las prolijas descripciones hechas por Ponz, Amador de los Ríos, Parro, Quadrado, Cedillo y González Simancas, en lo que concierne a la arquitectura y a los elementos mobiliarios, que aunque importantes para ambientarnos y vernos dentro de la sala capitular, no son fundamentales para nuestro cometido.

Los muros de la antesala capitular de la catedral de Toledo nos los encontramos cubiertos de pinturas, según nos permiten ver los armarios que ocultan la mitad inferior, dichas pinturas fingen una galería adintelada de techo artesonado con pilares de fustes decorados a candelieri, a modo de balconada fingida de la antesala donde se encuentra el espectador, que puede acceder con su mirada al vergel esquivando los jarrones de plantas florales colocados en el alféizar (figura 1). La estructura arquitectónica fingida de los tres vanos abiertos en la mitad superior del muro septentrional (en el meridional se repite pero interrumpida por una ventana), se compone de pilares corintios en dos planos, los más cercanos sustentan el arquitrabe y el friso corrido con los mismos motivos decorativos de los capiteles, pero invertidos y con pequeños jarroncillos entre ellos, cada espacio cúbico está adornado por guirnaldas colgadas delante y detrás mediante lazadas pinjantes, todo pintado con gran detallismo y un conocimiento naturalista profundo. En el lado derecho del muro de acceso desde la antesala a la sala capitular está pintado un gran jarrón con florecillas en el interior de una hornacina. Los lados largos de la antesala se unifican mediante la estructura arquitectónica descrita que deja ver tras ella el vergel de árboles frutales, flores y plantas en un único plano, está concebida espacialmente mediante una zona de fuga situada por debajo de los frescos visibles y un punto de vista preferente bajo y centrado, teniendo en cuenta la situación del espectador. Este estudio espacial de la arquitectura se ve interrumpido por la negación del espacio en el jardín visto a través de ella con una alineación de distintos tipos de árboles en un único plano, es decir, mientras que la disposición del jardín carece de profundidad, la arquitectura fingida denota un conocimiento de los planteamientos teóricos italianos sobre la perspectiva, la ventana albertiana de punto de fuga centralizado coincidente con la situación preferente del espectador ${ }^{29}$, pero con variacio-

\footnotetext{
${ }^{27}$ I. MAteo Gómez, «Sugerencias sobre el programa iconográfico de la sala capitular de la catedral de Toledo», Archivo Español de Arte, $\mathrm{n}^{\circ} 259-260,1992$, pp. 371-376.

${ }^{28}$ La documentación que relaciona a Juan de Borgoña con la antesala capitular tiene fecha de veinticinco de noviembre de 1510 cuando se paga la última cifra para completar los 49.366,5 maravedís a Luis de Medina por la pintura del zaguán, tasada por Juan de Borgoña, en: F. Pérez Sedano, loc. cit. nota 1, pp. 38 y 127. M. R. Zarco del Valle, loc. cit. nota 1, p. 114. J. A. Cé́n Bermúdez, loc. cit. nota 3, III, p. 45, añade al de Luis de Medina el nombre de Diego López en la factura de las pinturas de la antesala. S. R. PARro, loc. cit. nota 5, I, pp. 631-632, añade a Alfonso Sánchez, por ser los tres que solían trabajar juntos, y la dirección del trabajo a cargo de Juan de Borgoña.

${ }^{29}$ L. B. Alberti, De la pintura y otros escritos sobre arte, en latín De pictura, 1435, en italiano Della pittura, 1436, intr., trad. y notas de R. de la Villa, Madrid, 1999.
} 


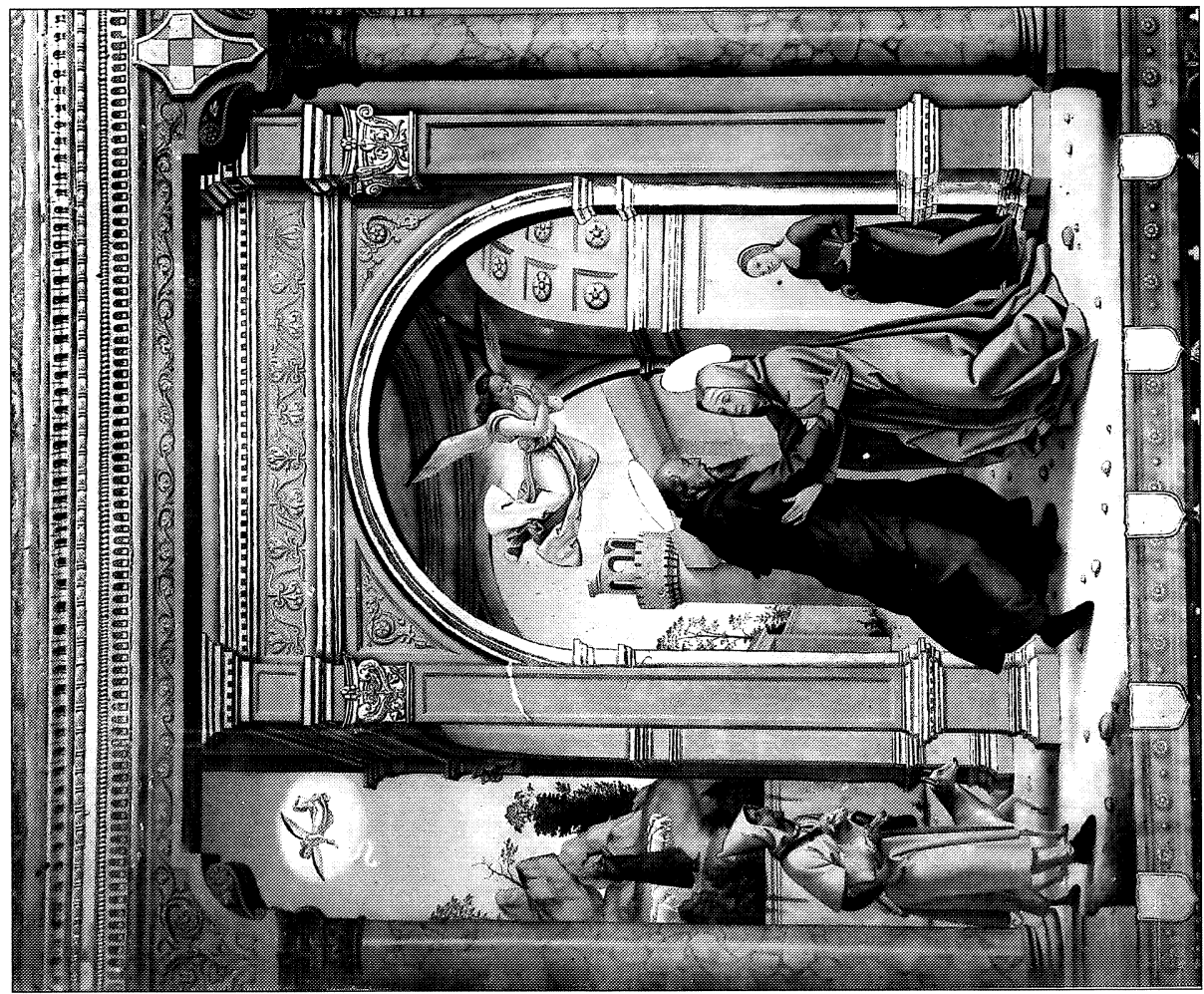

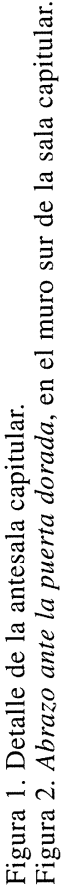

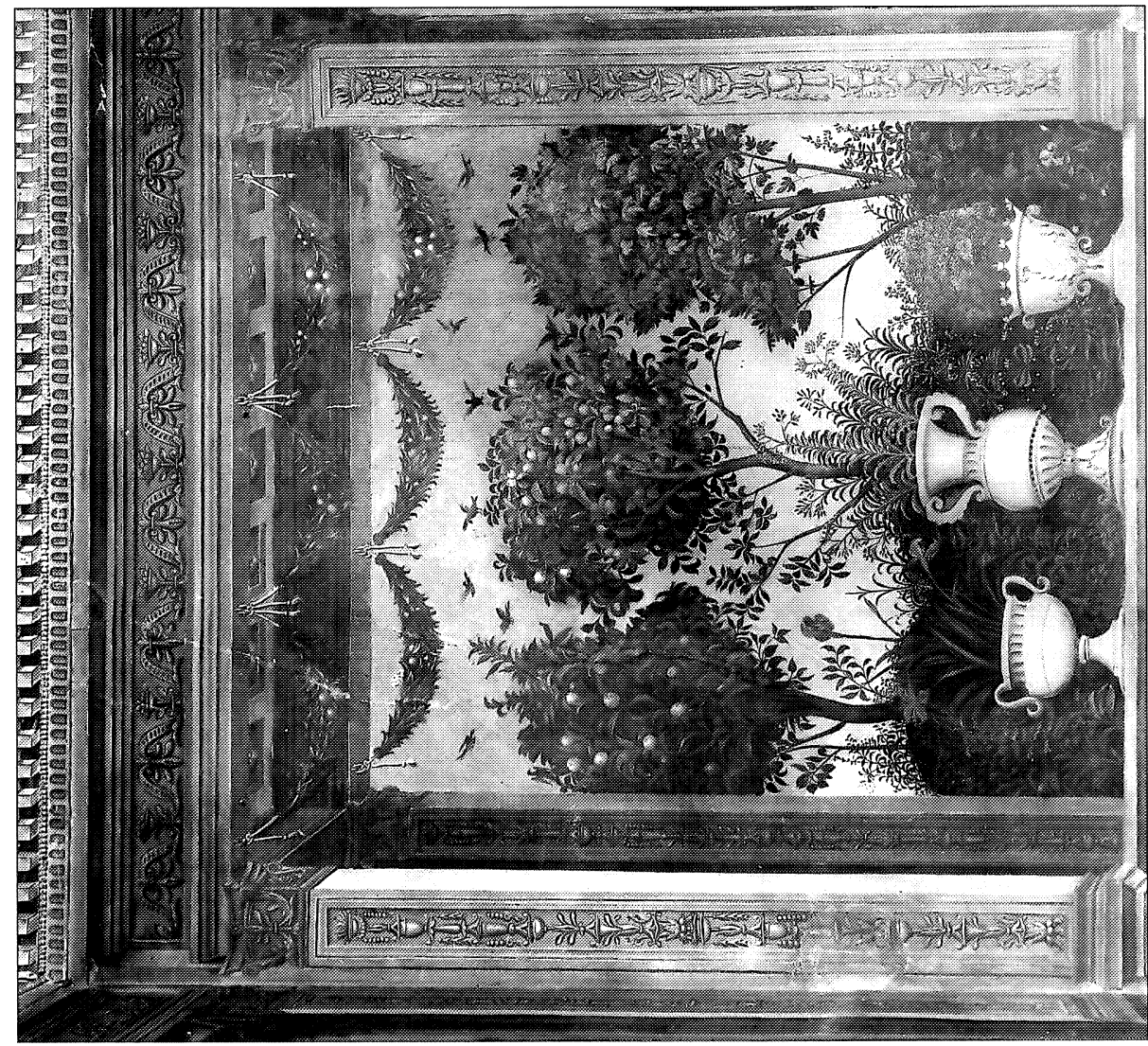


nes: el punto de fuga se convierte en una zona situada fuera de los límites de la ventana, por la altura donde se encuentran los frescos, y la composición espacial no se fundamenta en un pavimento de baldosas, en este caso imposible desde el punto de vista de las pinturas. Se convierte en una composición empírica, fruto de la observación directa de la naturaleza, de gran interés para un artista capaz de pintar un vergel de variedades vegetales. El director de la obra parece haber tenido presente la finalidad de la antesala, como lugar de paso, con una continuidad y unidad en la composición, permitiéndose flexibilizar el punto preferente de visión de los frescos. El asentamiento de los jarrones, perfectamente integrados en el espacio marcado por el alféizar, vistos desde abajo, introducen y ayudan, junto con los pilares, a crear la sensación de profundidad espacial mediante planos. El jarrón de la hornacina fingida en el lado derecho de la puerta de acceso a la sala, proyecta su sombra teniendo en cuenta la cercanía de la galería fingida a su derecha dirigiéndose hacia la izquierda. Al estar los dos muros laterales abiertos ficticiamente al exterior, se consiguen dos focos de luz que permiten alumbrar sendos pórticos enfrentados, pero la luz no proviene del mismo centro de cada galería, sino de un lateral. En el muro septentrional, la parte izquierda de los jarrones de variadas formas se ensombrece para crear volumen con el juego de claroscuro, el extremo derecho de esta galería queda oscurecido, en contraste con la claridad de los pilares del primer plano del extremo izquierdo.

$\mathrm{Al}$ acceder a la sala capitular nos encontramos un espacio rectangular dispuesto longitudinalmente hacia el este. Fijándonos únicamente en los cuatro muros, vamos a empezar nuestro recorrido siguiendo la cronología de las historias pintadas al fresco. Previamente debemos dar un vistazo rápido a todos los frescos para darnos cuenta de su disposición y estructuración. Siguiendo el modelo de la antesala, los muros laterales de la sala capitular se estructuran mediante una columnata fingida, compuesta por columnas elevadas sobre un alto plinto, fustes de mármol italiano pulido y capiteles corintios de variadas formas, zapatas decoradas con rosetas y filamentos vegetales rematan los ángulos superiores, unidos por un estrecho friso recorrido por decorativos tallos ondulantes. Esta columnata fingida invita a acceder a las historias contadas por detrás.

Con lectura de izquierda a derecha, la primera historia del muro sur es la del Encuentro ante la puerta dorada de san Joaquín y santa Ana (figura 2). La escena principal tiene lugar ante un pórtico de planta cuadrada con cubierta circular que da paso a una nave cubierta por bóveda casetonada. La simetría de la composición se ve marcada por las figuras abrazadas de san Joaquín y santa Ana, en el centro, y en los extremos, la del pastor a la izquierda y la de la doncella a la derecha ${ }^{30}$. El espacio se concibe desde un punto de vista de izquierda a derecha marcado por las columnas del primer plano, los pilares del templete, la vista del lado lateral izquierdo del pórtico, la espalda de san Joaquín, el frente de santa Ana y la disposición de sus nimbos paralelos a sus cabezas. Los pilares del pórtico corren oblicuos a la línea de tierra, de esta manera se marca la visión frontal escorzada ${ }^{31}$, característica de la perspectiva artificial, pero con una importante diferencia, su unilateralidad, la composición, para responder a la perspectiva de la pirámide visual, tendría que ampliarse hacia la izquierda con un espacio similar al de la escena del Abrazo. Con esta disposición compositiva simétrica centralizada en su distribución pero con un lugar preferente de observación lateralizado hacia la derecha, para seguir la dirección de las ortogonales que tienden a converger en el lado izquierdo lindando con el fuste de la columna estructuradora del muro, se consigue un espectador móvil, el punto de fuga se encuentra en el opaco del fuste, en primer plano, mientras que lindando con él se abre

\footnotetext{
${ }^{30}$ H. Damisch, El origen de la perspectiva, ed. en francés 1987, Madrid, 1997, p. 270, crea una tipología de simetrías formales atendiendo también a los volúmenes y espacios, y no únicamente a los contornos.

${ }^{31}$ Adoptamos la terminología de J. White, Nacimiento y renacimiento del espacio pictórico, $1 .^{\text {a }}$ ed. en inglés $1957,3 .^{a}$ ed. corr., ampl., 1987, Madrid, 1994.
} 
el espacio hacia un paisaje montañoso tras un murete paralelo a la línea de tierra, donde se narra lo ocurrido cronológicamente antes, el aviso del ángel a san Joaquín de la fertilidad de santa Ana. El escalonamiento marcado por las columnas, los pilares del pórtico cúbico, el murete de la izquierda y el muro de la derecha que corre paralelo al templete esquinado con una torre circular al fondo, son los elementos fundamentales en la creación del espacio ficticio abierto a diferentes flancos, que da un viraje al cambiar el punto de vista en el muro que enmarca el paisaje de la zona izquierda que corre hacia la derecha. Las líneas que nos marcan los elementos arquitectónicos, salvo las del murete de ladrillo que continúa en recoveco por detrás del pilar postrero del templete, incluyendo las columnas del primer plano pertenecientes al mundo del espectador, corren todas paralelas entre sí, consiguiendo la unidad espacial y una profundidad, también gracias a la disminución proporcional de los elementos. Resulta sorprendente coger el compás y ver el sutil y rítmico empequeñecimiento de los elementos paralelos, que van disminuyendo hacia el punto de fuga situado a la izquierda, así el capitel del pilar derecho de la arcada frontal del pórtico es ligeramente mayor al izquierdo, aunque este principio parece no justificar el tamaño del pastor con respecto a san Joaquín, prácticamente en un mismo plano, suponemos que debe de tratarse de una cuestión de simetría al paralelizar esta figura con la de la doncella. Los personajes se encuentran perfectamente asentados, sus posturas denotan movimiento a través del juego de pliegues y claroscuros, con los que también se consigue el volumen, ninguno de ellos dirige su movimiento en la misma dirección a las líneas de fuga ${ }^{32}$, san Joaquín en el Anuncio de su descendencia se encuentra de espaldas, al igual que el ángel y el pastor que dirige su caminar en sentido contrario, el ángel anunciador está paralelo a la línea de tierra, al igual que san Joaquín y santa Ana abrazados siguiendo la frontalidad del templete, y la doncella gira unos $45^{\circ}$, esta disposición crea una composición amena y variada.

Los espectadores de estas pinturas se encontraban sentados a dos alturas en el muro contrario. El Abrazo ante la puerta dorada está frente a los asientos perpendiculares más cercanos a la silla arzobispal, las miradas de los miembros del cabildo sentados quedaban por debajo de los frescos, a una distancia de más o menos tres veces la anchura de la pintura, todo esto es tenido muy en cuenta por Juan de Borgoña, porque a mayor distancia del espectador con respecto a la pintura, aumenta el campo de visión al disminuir el ángulo por debajo de $90^{\circ}{ }^{33}$, y consigue con una ligera y prolongada inclinación en la representación del suelo, una perspectiva decelerada, donde los personajes se mueven vistos desde abajo, con la línea de horizonte, más o menos, a la altura de la cintura de la figura humana.

La luz también conlleva un estudio particular para Juan de Borgoña, no solamente a la hora de crear volumen y plegar los paños, sino para la proyección de las sombras con zonas iluminadas y otras en semipenumbra. En el caso del Abrazo ante la puerta dorada la luz viene de la derecha, ligeramente baja y paralela a la pintura, las sombras se proyectan hacia la izquierda, y esta misma parte del templete queda ensombrecida, así como el arranque del interior de la cubierta, y la pechina. Otro foco se encuentra en la escena secundaria del anuncio de la fertilidad de santa Ana, donde el propio ángel anunciador funciona como foco de luz, y la sombra de san Joaquín se proyecta pequeña, al ser una luz cenital, y hacia la izquierda.

La escena continúa por detrás de las columnas que sirven de enmarque, pero no de ruptura con la siguiente, el Nacimiento de la Virgen, aún a pesar de que el ámbito espacial es completamente distinto, tiene lugar en una habitación interior de planta cuadrada con un espacio ad-

\footnotetext{
32 «Colineales» es el término utilizado por L. B. AlberTi (loc. cit. nota 29, p. 82) para las «cantidades» que no forman un triángulo y no ocupan ningún rayo visivo, es decir, las que siguen la dirección de los rayos visuales.

${ }^{33}$ Ídem, p. 73, «las superficies que, cuanto más próximo está el ojo a lo que mira, ve menos de ella y, cuanto más alejado, ve una parte mayor de la superficie».
} 
yacente a la derecha, donde se sitúa la cama de santa Ana (figura 3). El friso sostenido por las columnas se ve paralelizado con el que corre alrededor de la habitación por encima del arquitrabe y bajo un techo casetonado. El fondo de la estancia no se cierra, sino que a través de un vano adintelado de esquinas curvadas, que ocupa prácticamente todo el muro del fondo, se da paso a un patio porticado con salida a un exterior tapiado. Los personajes que componen la escena se distribuyen a ambos lados en dos grupos independientes, en el de las mujeres existe cierta simetría de volúmenes, en contraposición a la disposición en escuadra de los hombres a la izquierda. El eje central está marcado por la camita de la Virgen, las piernas del ama, continuando con el niño visible parcialmente.

Al igual que en el Abrazo, el punto de vista del pintor en el Nacimiento es de izquierda a derecha, dejando visibles el lado derecho de las estancias y parte de la espalda de san Joaquín. También es igual la visión, frontal escorzada unilateral, al ser paralelos a la línea de tierra el arquitrabe y el friso del muro abierto hacia el patio, que continúa por la cabecera dorada del lecho de santa Ana. El punto de fuga se sitúa a similar altura y tan excéntrico como en el Abra$z o$, coincidiendo con la columna izquierda del encuadre fingido, y marcando, más claramente en el Nacimiento, la posición preferente del espectador hacia la derecha, siguiendo el sentido de las ortogonales en profundidad, conseguida mediante el escalonamiento de las distintas figuras hasta el niño, y reforzada por la apertura de espacios secundarios que hacen perder la vista en el infinito, a través del paisaje divisado por la puerta de la derecha, donde las montañas se ven difuminadas. En esta escena Juan de Borgoña marca la proporción a través de la disminución de las baldosas, que son más pequeñas a medida que se acercan al punto de fuga situado entre el fuste y la cintura de san Joaquín. Sigue existiendo la unificación en el tratamiento espacial entre las columnas estructuradoras del muro y el espacio donde tiene lugar la escena, pero hay una diferencia en la coincidencia de las ortogonales, porque las marcadas por las columnas coinciden en un punto situado en el hombro de san Joaquín. Las figuras en variadas posturas, no condicionadas por las ortogonales, que esta vez están muy marcadas a través de los elementos arquitectónicos de cubrición y de la línea del pavimento con baldosas colocadas de manera romboidal, se integran perfectamente en el espacio, dejan traslucir bajo sus ropas las posturas de las piernas, mediante el juego de claroscuros de los paños, en este sentido destaca la figura zigzagueante de santa Ana, con las piernas en escorzo en sentido contrario al del tronco. El sentido oblicuo de la composición consigue ampliar el espacio, y el punto de vista es bajo para favorecer la contemplación de la escena desde una posición sedente.

La luz proviene de la ventana situada al lado de la cama de santa Ana (posiblemente el mismo foco de luz utilizado para el Abrazo), provoca el destello en el panel dorado que hace de cabezal, y proyecta las sombras hacia la izquierda. Hay un segundo foco luminoso en la puerta del fondo que deja ensombrecido el frente del niño y proyecta su sombra hacia delante.

El siguiente espacio en el muro meridional está ocupado por una ventana real que marca la fisura y el cambio de sentido en las líneas ortogonales.

En la Presentación de la Virgen en el templo volvemos a encontrar un pórtico de planta cuadrada abierto en sus cuatro frentes, los dos laterales únicamente en su mitad superior, el de la izquierda con mayor opacidad por la ventana enrejada, y el del fondo marca el arranque de una bóveda de cañón, precedido por una escalinata, y cubierto de manera circular (figura 4). La parte derecha de la composición es exterior, se ve interrumpida por un luneto sostenido por zapatas sobre columnas, sin evitar este parapeto la continuidad del espacio hacia un paisaje con árboles y montañas, que no faltan prácticamente en ninguna de las composiciones.

El número de personajes sigue aumentando progresivamente desde la primera escena, y no sólo se distribuyen en distintos planos, sino también en altura, con la diferencia entre los personajes que reciben a la Virgen y los que la despiden, el primero de los grupos se desentiende 

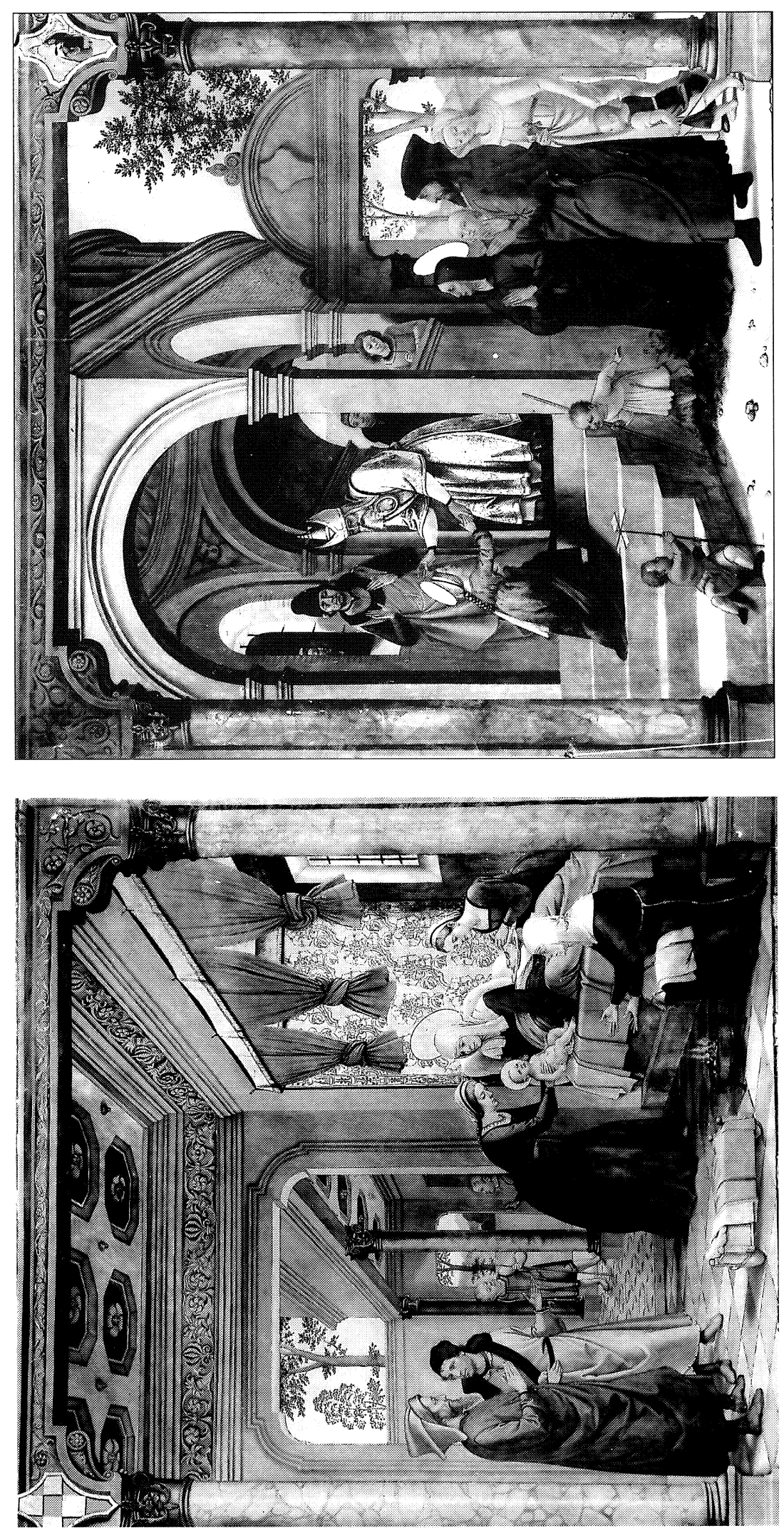
del otro, manteniendo el nexo de comunicación a través del joven apoyado en el pretil. El grupo de santa Ana y san Joaquín dirige toda su atención sobre la Virgen niña que asciende hacia el interior del templo, los niños juguetones llenan el vacío de la izquierda y cargan de movimiento la escena, porque además provocan el intento de huida del tercer niño cogido de la mano de su madre. Juan de Borgoña repite la visión frontal escorzada en la disposición del templo, que marca la dirección de las ortogonales hacia un punto de fuga excéntrico situado en el fuste de la columna derecha a la altura de la cintura de san Joaquín. Se abandona la unilateralidad, al hacer coincidir el punto de fuga con el de la escena siguiente, la Anunciación, el fuste es el eje de simetría de la proyección espacial entre las dos escenas ${ }^{34}$. El punto de vista del pintor en la Presentación es de derecha a izquierda, al mostrar la monumentalidad del templo, visible en una segunda planta que se pierde en altura, la espalda de san Joaquín y del niño impaciente, y como en el resto de las composiciones, a través de los plintos, capiteles y zapatas de las columnas del primer plano, estos elementos del encuadre marcan las líneas ortogonales hacia un punto de fuga más elevado que el de la escena, al igual que en la Anunciación. El eje entre la Presentación y la Anunciación, la columna compartida por las dos pinturas, es el lugar preferente, según el sistema albertiano, del punto de vista del espectador, coincidente en las composiciones frontales escorzadas bilaterales con el de fuga, pero en este caso chocamos con un fuste de mármol en primer plano, por tanto, el espectador debe girar su mirada a un lado y otro, siguiendo las líneas de fuga, para obtener una correcta visión. En esta parte de la sala capitular no llegaban a sentarse los canónigos, era una zona utilizada como secretaría, pero mantiene la misma inclinación del suelo, igual para todas las escenas de este muro meridional, y el punto de vista bajo. La profundidad del espacio en la Presentación se consigue a través de los peldaños de la escalera, de los pilares sucesivos del templete y del arranque de la bóveda, aparte del escalonamiento de los personajes en diferentes planos, la luz, al irse oscureciendo en el interior del pórtico del templo, y los colores, que se aclaran en profundidad contrastados con los más intensos de las figuras en primer plano, la disminución proporcional de los elementos arquitectónicos y las figuras, a medida que se alejan del primer plano.

El foco de luz en el grupo protagonizado por santa Ana y san Joaquín de la Presentación se sitúa a la izquierda, las sombras se proyectan hacia la derecha, sombras algo alargadas que denotan una media altura y total lateralidad del foco luminoso. Existe otra fuente de luz diferente que produce sombras hacia el fondo en el grupo del templete.

La Anunciación es la última escena del muro meridional donde volvemos a encontrar elementos arquitectónicos y una disposición espacial similares a las anteriores (figura 5). Bajo un templete de planta cuadrada sostenido por columnas se dispone la Virgen a recibir el mandato divino como si se encontrara en un altar, la hornacina avenerada a su izquierda y el paño en el fondo propician el marco donde resaltar su menuda figura. La escena se encuentra limitada por un muro que se ve interrumpido en su parte frontal por una torre cilíndrica rematada por un belvedere poligonal cubierto con una estructura piramidal, elemento renacentista sobre una arquitectura de aire románico. El muro parece provenir de la Presentación para no interrumpir bruscamente una escena al iniciarse la siguiente. El número de personajes, con respecto a otras escenas analizadas, ha disminuido notablemente, el paisaje se ve limitado a dos altísimos árboles asomando por encima del muro de ladrillo, pero nos encontramos dispersos por el suelo del patio hierbecillas y tallos tratados con gran minuciosidad. Ya hemos visto, al referirnos a la Presentación, cómo en la Anunciación el punto de vista adoptado al pintar el fresco es de izquierda a derecha, según delata la posibilidad de ver parte del interior de la hornacina, el fren-

${ }^{34}$ A. Ávila, loc. cit. nota 23, p. 553, destaca la coincidencia del punto de fuga entre la «Presentación» y la «Anunciación». 

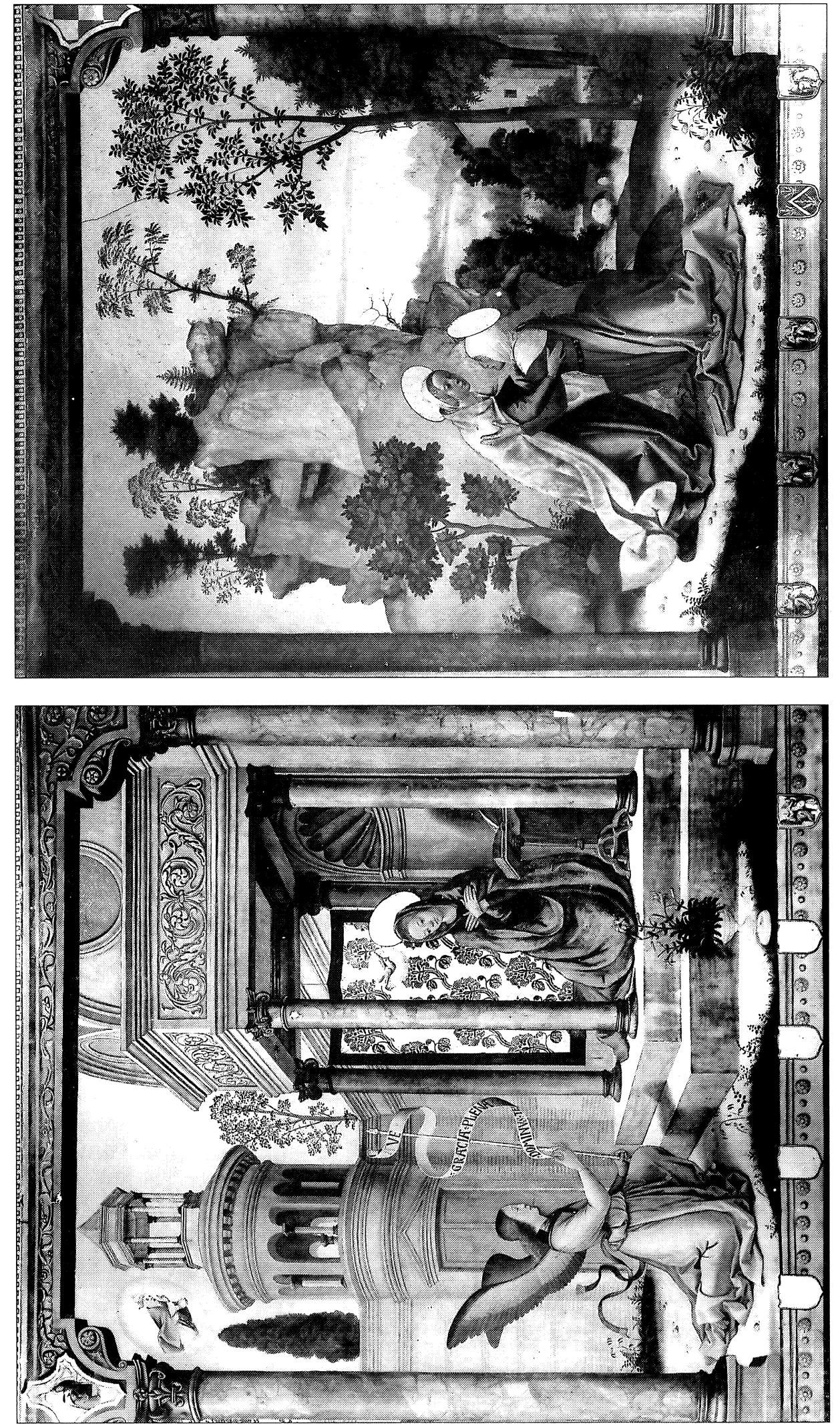

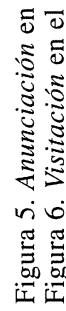


te del templete, que se sitúa paralelo a la línea de tierra, y el lado izquierdo de la zapata y el plinto de la columna derecha del primer plano. La disposición es contraria a la de la Presentación, obligando al espectador a mirar hacia el punto de fuga desde el lado contrario, para que su vista corra paralela a las líneas ortogonales, la profundidad se ve marcada por dichas líneas, con el jarrón de flores del primer plano, seguido escalonadamente de las columnas sustentantes del templete, y con una disposición del ángel más cercana que la Virgen. En el análisis de la profundidad hay que destacar la visión del interior del piso superior horadado por vanos geminados de la torre cilíndrica, que dejan ver sus contrarios al otro lado, esta disposición delata la gran profundidad que consigue Juan de Borgoña en sus pinturas, porque en una composición cerrada, a través de un detalle como éste, parece tener en cuenta el ángulo de visión y su disminución a medida que aumenta la distancia.

La luz vuelve a provenir del lado izquierdo, las sombras se proyectan hacia la derecha, paralelas a la línea de tierra. No es posible que Dios Padre sea el generador de la luz, porque se encuentra demasiado alto y las sombras son alargadas, fruto de una fuente luminosa a una altura media. La torre parece iluminarse desde el exterior, más allá del muro, al quedar ensombrecida la parte interna que mira hacia nosotros.

El muro septentrional, también con lectura de izquierda a derecha, comienza con la Visitación (figura 6). El escenario cambia completamente al situarse las figuras de la Virgen y santa Isabel en un entorno paisajístico, carente de toda referencia arquitectónica, salvo la pequeña casa de ladrillo que simplemente forma parte del escenario sin jugar ningún papel estructurador del espacio. A pesar del carácter externo del ámbito donde se desarrolla la acción, Juan de Borgoña no abandona la negación del espacio en una parte de la composición, para dejar la otra abierta al infinito, la zona izquierda se ve interrumpida por la presencia de una montaña rocosa donde crecen árboles de distintos tipos ${ }^{35}$; la derecha, a través de diferentes detalles, el puente, el riachuelo, los árboles en la vereda, continúa sin fin difuminándose las formas. Podemos comparar la disposición de la Virgen y santa Isabel con la de san Joaquín y santa Ana del Abrazo ante la puerta dorada, existe un paralelismo entre las figuras de la Virgen con san Joaquín y santa Isabel con santa Ana, aunque con respecto a la línea de tierra los padres de la Virgen se mantienen paralelos a ella, y las dos mujeres abrazadas se disponen oblicuas en sentido contrario a la dirección de las líneas ortogonales marcadas por los plintos de las columnas del primer plano, van a ser únicamente estas líneas las que nos descubran la situación del punto de fuga en la parte baja del fuste de la columna derecha. Juan de Borgoña ve la escena de la Visitación de derecha a izquierda, nos deja ver la espalda de santa Isabel, el lado derecho del plinto y la zapata de la columna izquierda, existe otro punto de vista al hacer visible en el riachuelo el lado derecho de los ojos del puente y la parte frontal de la casa, dispuesta oblicua de izquierda a derecha. La composición se ve centralizada por las dos figuras, de ellas arranca el escalonamiento en profundidad, la Virgen se encuentra en un plano algo más profundo con respecto a santa Isabel, detrás vienen las rocas, el arbusto, hasta llegar a la mole rocosa con distancia ascendente. El punto de vista del espectador es muy bajo y lejano, por este motivo el espacio pictórico es concebido con un suelo estable, no demasiado inclinado, donde poder hacer mover las figuras perfectamente asentadas.

Existen dos focos de luz, uno proveniente de la izquierda que recae sobre la espalda de la Virgen y deja en sombra la de santa Isabel, y el segundo viene del fondo, ilumina la parte derecha, eminentemente campestre, con el río, el puente y la casa.

\footnotetext{
${ }^{35}$ Evangelio de san Lucas (I, 39): «En aquellos días, se levantó María y se fue con prontitud a la región montañosa, a una ciudad de Judá», así se describe el inicio de la Visitación en el evangelio y podría justificar la presencia de la montaña rocosa en la escena representada por Juan de Borgoña.
} 
Va a resultar inevitable una mayor brusquedad al pasar de una escena desarrollada en el exterior a la Presentación de Jesús en el templo ${ }^{36}$ concebida en el interior de una basílica con dos naves visibles separadas por pilares compuestos de haces de columnas, con una arcada de altos arcos apuntados que dejan ver tras su luz la bóveda nervada de la nave lateral del lado del evangelio, con una tribuna abierta a la nave mediante vanos geminados de medio punto, y con un discreto claristorio de vidrieras visibles únicamente en la cabecera (figura 7). La nave central cubierta por bóveda de terceletes continúa hasta la cabecera poligonal donde se encuentra el arca dorada, por detrás de los arcos apuntados y doblados de la cabecera puede adivinarse un deambulatorio con lunetos y óculos horadados en el muro exterior, la nave lateral se ve interrumpida por el crucero. La acción se sitúa en un plano cercano al espectador, a los pies de la nave central, mediante un grupo de figuras que ocupan el espacio escalonadamente desde san Pedro, a la izquierda, enfrentado a él otra figura masculina, ambos de riguroso perfil, la doncella en el lado izquierdo de san Pedro, la Virgen María con el Niño y Simeón detrás del altar sobre un pedestal poligonal ${ }^{37}$, y en un plano postrero la profetisa Ana. El espacio del crucero y de la cabecera se ve despejado de figuras, consiguiendo dar profundidad a la escena mediante el seguimiento de la girola por la nave lateral del evangelio, la secuencia de haces de columnas y los distintos tramos de la bóveda. La composición concebida de derecha a izquierda deja ver parte del frente de san Pedro y la espalda de su contrario a la derecha, el lado derecho del altar, el frontal del muro de la izquierda de la nave principal más ancha, y el muro límite norte del templo donde se abre una puerta de acceso, las líneas que marcan la fuga del espacio corren oblicuas hacia el fuste de la columna derecha, límite con la siguiente escena de este muro septentrional, todas coinciden, incluyendo las de estas columnas-marco, en un mismo punto situado por debajo de la cintura de la figura masculina pensativa, del lado derecho, en el límite con la columna. La disimetría de la composición perspectiva, como ya hemos dicho para otras escenas, fruto de la inexistencia de otro espacio también convergente en el punto de fuga, y formar una visión frontal escorzada bilateral, se palia con la simetría en la distribución de los personajes, san Pedro y su frontero enmarcan la composición central del altar con Simeón y el Niño, creándose un círculo alrededor formado por los otros personajes, que se acumulan en mayor número en el flanco izquierdo, debido a esa visión de derecha a izquierda, que amplía el espacio hacia ese lado. El espectador se ve atraído por esa dirección de izquierda a derecha de las líneas fugales, su mirada recorre la nave del templo, interrumpida por los personajes, hasta topar con el arca. Puede resultar extraña la disposición de los tramos de la bóveda de la cabecera, algo forzado su giro hacia la derecha, pero simplemente es un efecto de la vista, porque al trazar la línea que une las claves de la bóveda viene a coincidir en el punto de fuga, la profundidad está marcada por la disminución algo empírica de los personajes, dispuestos paralelos a la dirección de la nave del templo. Sin pretender ser demasiado insistentes, volvemos a remarcar el punto de vista del espectador, situado distante y por debajo del límite inferior del fresco que obliga a una progresiva inclinación del suelo, en este caso con baldosas decorativas, donde se asientan las figuras, expresivas a través de sus manos, y voluminosas en sus ropas donde incide la luz en los pliegues abundantes.

La luz se dirige en la misma dirección que en la Visitación, con la que comparte también el punto de vista de izquierda a derecha y la excentricidad del punto de fuga, situado en el límite derecho de la composición, precisamente en el opaco del fuste de la columna. El foco

\footnotetext{
${ }^{36}$ Algunos autores han querido ver en esta escena la Circuncisión, pero según la descripción del evangelio de san Lucas de la presentación de Jesús (II, 22-38), esta escena responde a este tema, con el añadido de algunos personajes.

37 Forma como la del belvedere de la torre en la Anunciación. En esta escena y en la Presentación del Niño en el templo coincide el estampado del paño colgado de los capiteles de las columnas del templete, donde se arrodilla la Virgen, y el de la casulla de Simeón.
} 


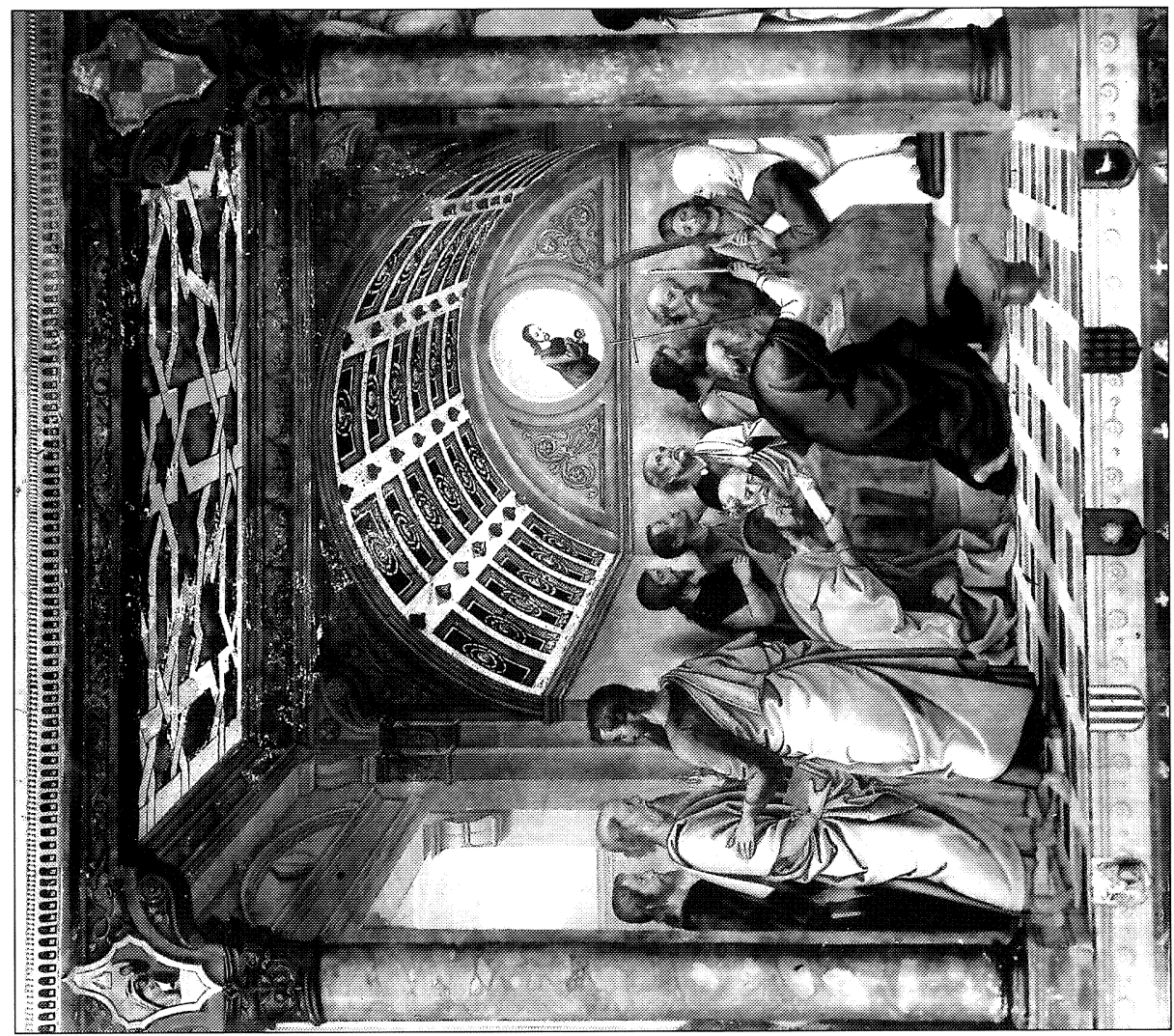

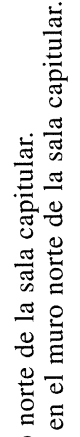
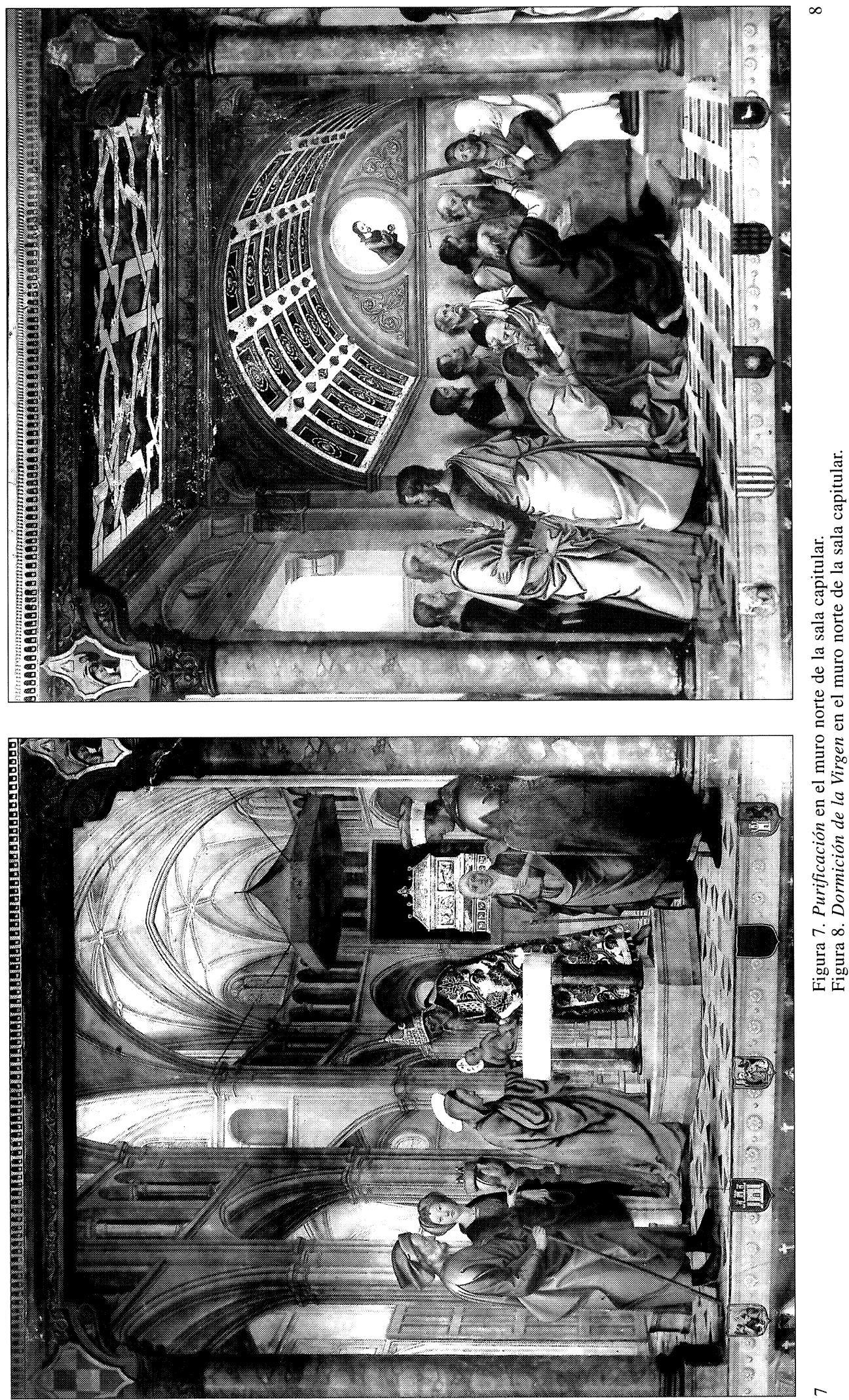

苛

$\sqrt{2} \frac{2}{2}$

:

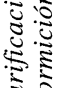

:

$\pi \infty$

营兽 
luminoso parece venir de la escena anterior, de izquierda a derecha, a través de la casi invisible puerta del muro norte, proyectando las sombras horizontales a la línea de tierra. Como viene siendo habitual en las pinturas de la sala capitular, existe un segundo foco que ilumina la parte frontal del crucero, para conseguir ese juego de luces y sombras, de zonas iluminadas y en penumbra, dando volumen y profundidad.

Se produce un corte cronológico, porque para las escenas de la Pasión de Cristo se reserva el muro frontero a la puerta de acceso, y en el septentrional se continúa con la Dormición de la Virgen representada en un interior abierto a un segundo espacio a través de una puerta desde donde se divisa un murete de ladrillo, que deja ver por encima suyo un paisaje completamente difuminado, la estancia donde tiene lugar la escena se ve precedida por un espacio de planta cuadrada con cubierta artesonada, limitada por semipilares embebidos en el muro, las columnas del primer plano, compartidas con las escenas colaterales a la Dormición, parecen formar parte de este recibidor y ser el límite frontal del espacio cúbico (figura 8). El lecho de la Virgen está en un segundo espacio cubierto por bóveda de cañón con casetones de rosetas en relieve, al fondo el luneto decorado con tallos y flores, abierto en el centro por un óculo, donde aparece Cristo para recoger el alma de su madre. Las figuras, contrariamente a la escena de la Presentación de Jesús, se concentran en el fondo, pegadas al muro y rodeando el lecho sagrado, no prescinde Juan de Borgoña de los personajes que introducen al espectador en el espacio fingido a través de una disposición diagonal de izquierda a derecha, en primer plano se sitúan dos de los apóstoles hablando, y un tercero entrando desde el patio, en la zona abovedada, a los pies de la cama, paralela al plano de tierra, dos apóstoles leen en el mismo libro y un tercero alumbra el rostro de la Virgen desde su lado izquierdo, el resto de los personajes desciende ligeramente hacia la cabeza de la Virgen. Se sigue manteniendo el sentido de derecha a izquierda en la mirada del pintor, y la excentricidad en el punto coincidente de las líneas de fuga en el límite del fuste de la columna derecha, la visión preferente del espectador es paralela a la de la nave gótica de la Presentación, dirigiéndose su mirada hacia la profundidad de la estancia abovedada, viéndose desviada hacia la izquierda cuando topa con el vano abierto al infinito. El pavimento solado con baldosas se ve despejado de figuras y Juan de Borgoña, para equilibrar la composición, coloca un almirez y un cajoncito, a modo de mesilla de noche, sobre el que descansan un libro y unos frutos, precedente de un bodegón. En esta escena hay que destacar el juego de elementos arquitectónicos dispuestos en diferentes planos, según la secuencia de estancias, este juego de formas se ve también en las variadas posturas que adoptan los apóstoles, sin encontrarse obligados a seguir la dirección de las ortogonales, aparecen personajes de frente, de perfil, de tres cuartos, de espaldas, tumbados, arrodillados, agachados y estantes, acentuado el dinamismo con el movimiento de sus ropas y el juego de claroscuros. La visión frontal escorzada unilateral se puede entender claramente observando la vista frontal del lateral de la cama de la Virgen y la oblicua de las líneas que conforman las estancias dirigidas hacia la derecha, la profundidad, marcada por la disminución del tamaño de las baldosas del pavimento y de los casetones dorados de la bóveda, resulta convincente pero sin un respaldo matemático. En esta escena, con una continuidad del techo entre las dos estancias contiguas, podemos ver la inclinación del plano de cubierta mucho más acelerada que la del suelo, fruto de la visión de sotto in su.

La luz, como viene siendo habitual en este muro septentrional de la sala capitular, proviene de la izquierda, de la puerta abierta, con un segundo foco de luz que irradia sus rayos desde el óculo frontero con la figura de Cristo.

La dirección oblicua hacia la derecha de las tres primeras escenas del muro septentrional se ve interrumpida por la visión exactamente frontal de la Asunción con un planteamiento más cercano al de la perspectiva piramidal de Alberti (figura 9). Todas las ortogonales se dirigen 

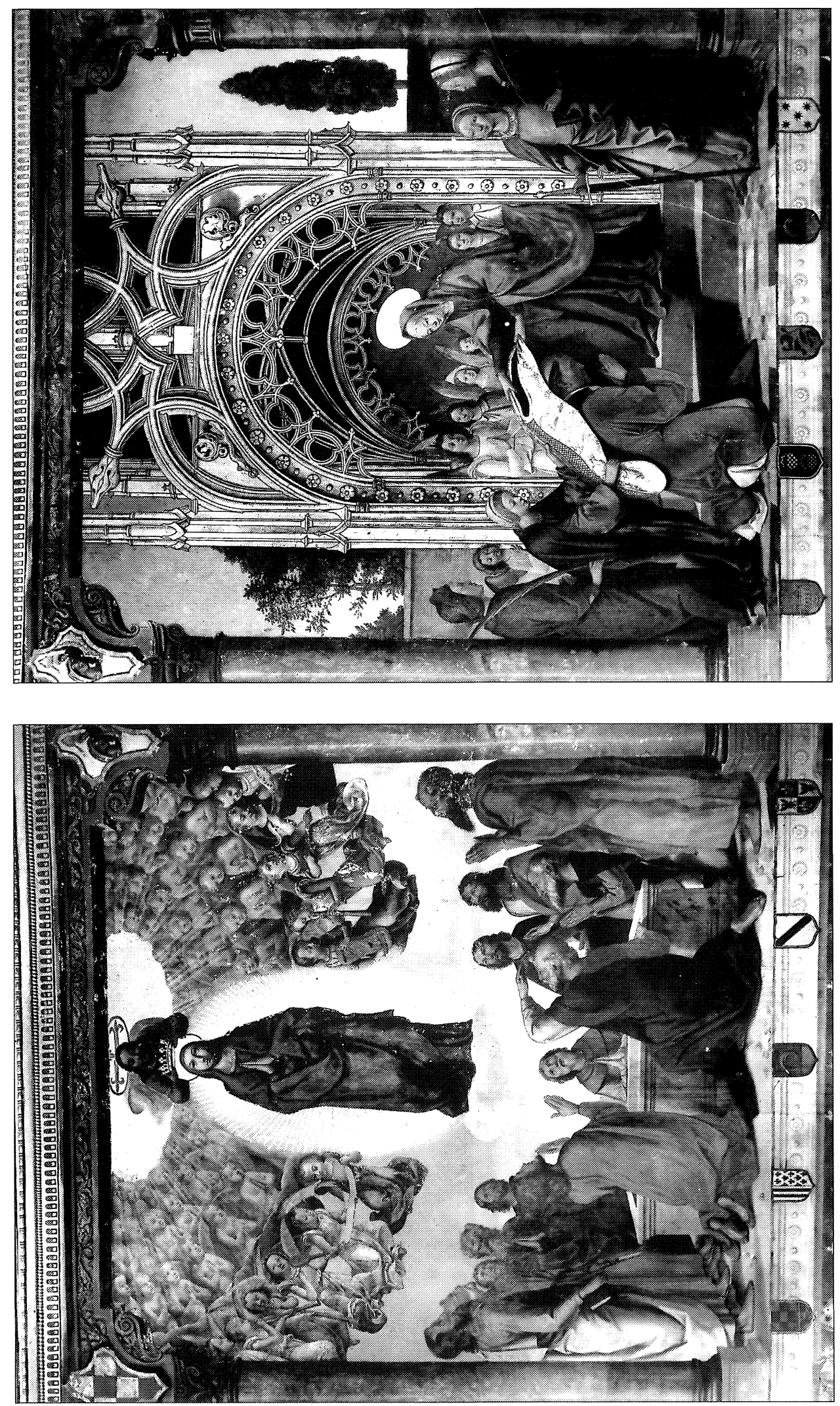

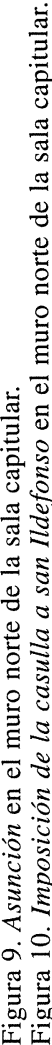


hacia el centro, en el punto preciso que forman las manos unidas del apóstol arrodillado detrás del sepulcro, la simetría bilateral hace corresponder unos personajes de un lado con otros fronteros, el sepulcro marca las líneas ortogonales convergentes, y las figuras van disminuyendo desde un punto de vista bajo, que coincide con el de fuga, las cabezas no se alinean, sino que según los planos van descendiendo en altura marcando la profundidad ${ }^{38}$. La composición se divide en dos partes, una superior y otra inferior, la figura humana cubre prácticamente todo el espacio, y es a través de los personajes cómo se consigue el sentido de profundidad y concavidad de la parte superior con la Virgen en el centro completamente frontal, enmarcada por una cúpula de ángeles abierta en su centro para la figura de Cristo ${ }^{39}$, los apóstoles rodean en la parte inferior el sepulcro descubierto. Se podría destacar los escorzos de las dos figuras arrodilladas del primer plano con una ejecución basada en un profundo conocimiento del natural para conseguir dos figuras en posturas convincentes, pero el escorzo más llamativo, a pesar de su situación postrera, es el de la cabeza barbada del apóstol arrodillado de la derecha, que mediante un juego de luces y sombras sobre la barba cana, consigue hacerla visible desde abajo.

La luz sigue viniendo de la izquierda, pero algo oblicua hacia el fondo, los volúmenes proyectan sus sombras hacia la derecha, esta luz lateral se ve contrarrestada por el foco principal procedente de la mandorla de rayos luminosos que rodea a la Virgen.

La última escena del muro septentrional corresponde al tema eminentemente toledano de la Imposición de la casulla a san Ildefonso con las mismas características de historias anteriores (figura 10). La escena se narra ante un templete central, visible frontalmente, abierto por un arco de medio punto adornado con flores en la parte cóncava ${ }^{40}$, la concavidad se hace patente mediante el sombreado y la diferencia de altura en los diminutos capiteles de las finísimas columnillas que delatan un retraimiento del arco, con dos planos dispuestos en profundidad, el frente del templete enmarcado por dos pináculos en su parte superior se adorna con una tracería gótica que continúa más allá de los límites pictóricos para producir una sensación de monumentalidad. La zona inferior, protagonizada por la Virgen, está cubierta por bóveda de terceletes que se confunde con el juego de la crestería que adorna la bóveda en los dos lados, pudiéndose ver claramente la diferencia de tamaño entre la del plano más cercano al espectador y la que topa con el límite del templete, por detrás de éste corre un muro, como en otras composiciones ya descritas, que deja libre la parte superior para hacer visibles las copas de los altísimos árboles en dos pequeños espacios a derecha e izquierda. Las figuras se distribuyen en el exterior y en el interior del templete, de forma escalonada se suceden en el espacio adoptando distintas poses para amenizar la escena, en el exterior cuatro santas son representadas, dos a dos, a ambos lados del templete, el interior está presidido por la Virgen con un movimiento hacia delante, para colocar la casulla al santo arrodillado en sentido oblicuo, contrario al de la Virgen, los angelitos rellenan el espacio para marcar la profundidad del templete. Juan de Borgoña utiliza un suelo pavimentado, las líneas de unión de las baldosas marcan las ortogonales dirigidas hacia el centro, en un punto situado entre la cabeza de san Ildefonso y la figura de la Virgen, así, al igual que en la escena anterior, la composición es centralizada bilateral, con un punto de vista central coincidente con el preferente del espectador, que no podemos olvidar se encuentra por debajo de la pintura y alejado de ella.

El foco de luz parte de la izquierda y proyecta sombras oblicuas desde este lado hacia la derecha, este sentido lo marca claramente la sombra proyectada por san Ildefonso y su casulla

${ }^{38}$ L. B. AlBerTI, loc. cit. nota 29, p. 86, recomienda la disminución de los personajes en profundidad pero manteniendo la misma altura de la cabeza mientras ascienden los pies.

${ }^{39}$ La Asunción fue restaurada en 1586 por Blas de Prado y en 1646 por Francisco de Aguirre, fruto de estas restauraciones debe de ser la extraña y drástica difuminación de los ángeles por encima de los músicos del primer semicírculo, y de algunos rostros distantes a los tipos característicos de Juan de Borgoña.

${ }^{40}$ La misma decoración combinando flor y punto del friso, límite inferior de las escenas. 
sobre los peldaños, pero la escena brilla por sí misma gracias al reflejo de la luz sobre los adornos dorados del templete.

Finalizado el estudio de las escenas de los muros laterales, vamos a dirigir nuestra mirada hacia el muro oriental donde se narra, de izquierda a derecha, el Descendimiento de la cruz, el Llanto sobre Cristo muerto (figura 11) y la Resurrección. La composición unificada de las tres escenas se desarrolla en un paisaje continuo detrás de las columnas, que también en este muro estructuran y sirven de nexo entre el espectador y las historias, a pesar de que las dos primeras sucedían en un mismo lugar, Juan de Borgoña no repite el paisaje en una y otra escena sino que lo continúa, las líneas de fuga convergen en el cuerpo de Cristo yacente, y se aumenta el canon con respecto a las escenas de los muros laterales, utilizando todo el espacio mural para conseguir el efecto desde el muro contrario, el de acceso a la sala capitular.

La composición en el Descendimiento se ve marcada por la cruz de Cristo en el centro, igual que en el Llanto. La disposición de las figuras de la primera escena conforman dos diagonales, una siguiendo las cabezas de Pedro de Arimatea, Cristo y la Virgen, san Juan y una de las santas mujeres en el lado izquierdo; la otra curvada recorre las cabezas de Nicodemo, María Magdalena y la santa arrodillada prácticamente de espaldas. Con esta distribución de las figuras consigue llenar los primeros planos, para extender hacia el fondo el paisaje montañoso de roquedo, propio de una escena dramática. La profundidad, sin puntos de referencia arquitectónicos, es marcada por el escalonamiento de los personajes y el paisaje, así como con los límites del travesaño de la cruz y la escalera que se viene hacia nosotros para apoyar en el mismo madero. En el Llanto, el centro de las tres composiciones, al dirigirse oblicuamente hacia ella las otras dos escenas, la cruz ocupa todo el espacio y las figuras se concentran en la mitad inferior, no vamos a insistir en los escorzos de las figuras, en el volumen con el juego de claroscuros en los paños, pero estas escenas del fondo oriental están plagadas de detalles que demuestran la calidad de Juan de Borgoña para resolver problemas perspectivos surgidos en cada figura. En el Descendimiento rompe la profundidad con el macizo que ocupa gran parte del fondo, para dejar una apertura por la que nos lleva hasta una torre, único detalle arquitectónico de los frescos del muro oriental. En la Resurrección las líneas del sepulcro y del entarimado escalonado donde se asienta, ayudan a dirigirnos hacia el centro situado en la escena anterior, la figura frontal de Cristo marca el eje de simetría de la composición, dividida lateralmente en dos, en el lado derecho el soldado en contraposto, vuelto hacia Cristo, y el que se asoma por detrás del sepulcro con casco y alabarda; en la izquierda también dos soldados, uno dormido sobre los peldaños y otro iza su brazo en señal de sorpresa. Las figuras se escalonan en dos planos en profundidad divididos por el sepulcro, en el más cercano a nosotros el soldado dormido y el armado con coraza, escudo y lanza; en el lejano, el sorprendido y el asomado por detrás del sepulcro. El fondo de la composición está ocupado en el lado derecho por la cueva de la sepultura, y en el izquierdo se abre el paisaje mediante planos de profundidad. No falta tampoco el muro de ladrillo a manera de parapeto y separación entre la zona principal y lo que podría ser mero fondo, «los lejos».

Tomados individualmente el Descendimiento, el Llanto y la Resurrección, las dos escenas laterales responderían a visiones escorzadas y la tercera centralizada, pero la concepción de la pintura es unitaria para conseguir una visión óptima desde la distancia. La luz también es unitaria, proviene de la derecha, posiblemente teniendo en cuenta la iluminación de la sala capitular a través de la ventana del muro meridional, proyectando las sombras de derecha a izquierda oblicuamente.

La última historia situada en el muro de acceso, sobre la puerta de entrada desde la antesala, es el Juicio Final, describirla minuciosamente sería misión imposible por la cantidad de personajes pintados: Cristo, la Virgen, san Juan Bautista, los apóstoles, los condenados y bien- 


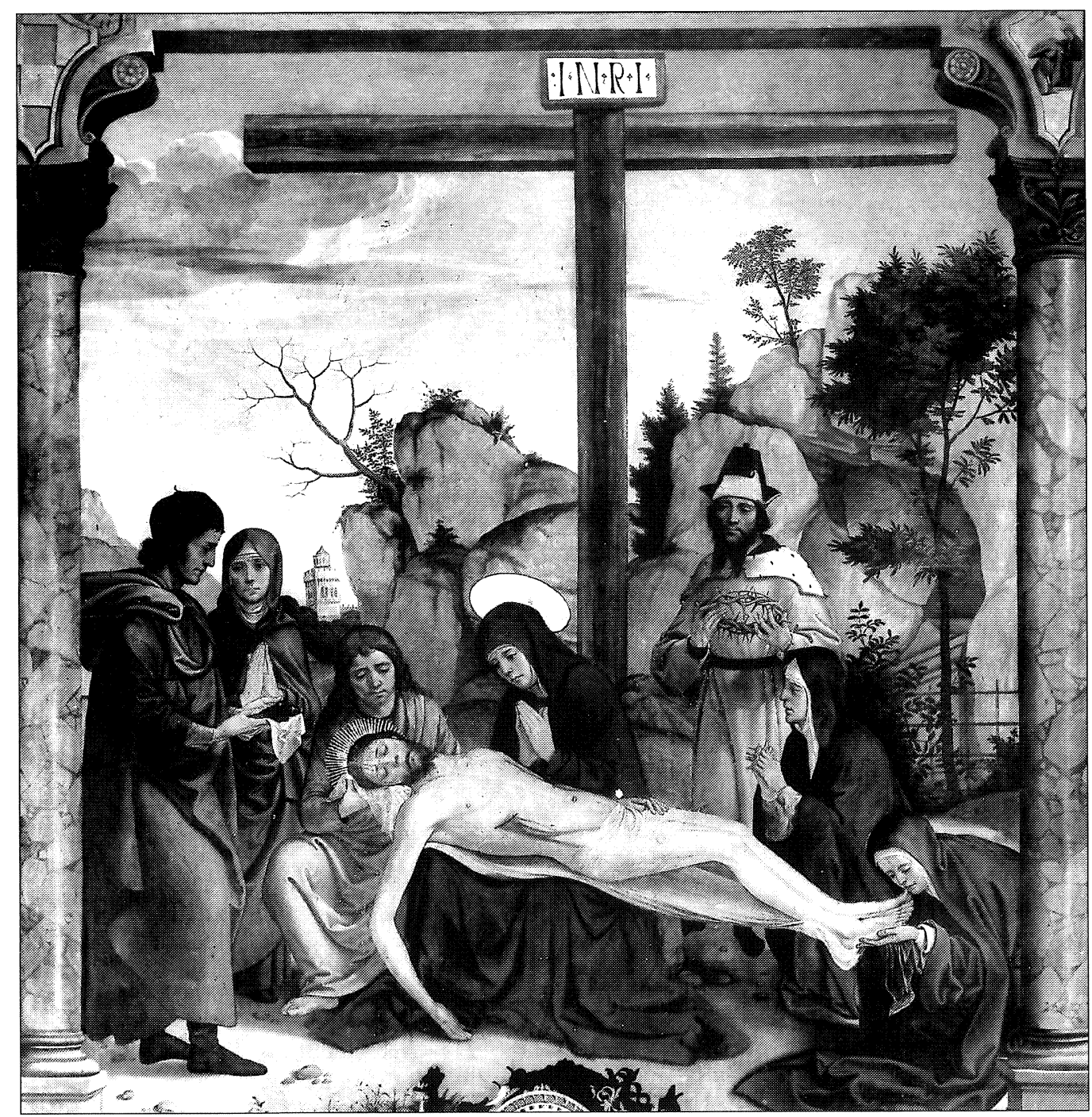

11

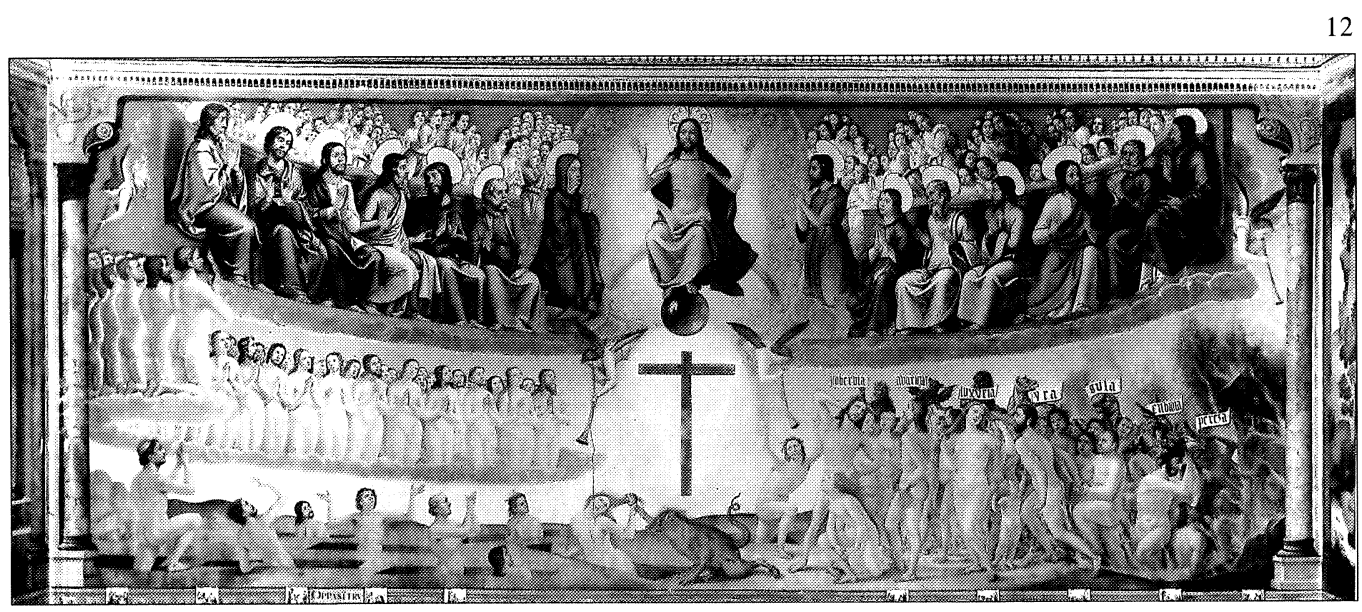

Figura 11. Llanto sobre Cristo muerto en el muro este de la sala capitular.

Figura 12. Juicio Final en el muro oeste de la sala capitular. 
aventurados, y la multitud de angelitos que terminan de llenar el espacio (figura 12). La composición se divide, partiendo del eje formado por Cristo Salvador y la cruz, en dos mitades a izquierda y derecha. La primera de ellas está dividida a su vez en tres horizontales formadas por el suelo de sepulturas abiertas, la elipse de la nube donde se arrodillan los elegidos y, siguiendo la misma forma cóncava, el banco de los apóstoles y la Virgen coronados por las cabecitas de los ángeles; a la derecha, los condenados forman un amasijo descendente hacia el extremo, formando una diagonal, y por encima de ellos la continuación del banco de los apóstoles presidido por san Juan Bautista. El estudio de la perspectiva parte de las columnas, que esta vez únicamente enmarcan el muro sin dividirlo, las ortogonales se dirigen hacia el punto de fuga situado en la base de la Cruz, pero, como viene siendo habitual, la profundidad se consigue mediante el escalonamiento de las figuras en diferentes planos, esta vez, incluso, Juan de Borgoña consigue dar forma cóncava al muro occidental de la sala capitular. El plano más cercano lo ocupa Cristo en la parte alta acompañado por la Virgen y san Juan Bautista, a los lados el banco de los apóstoles, visto de sotto in su, se curva hacia nosotros, de la misma manera que la nube de los salvados. La luz proveniente de Cristo acentúa el volumen de los cuerpos y proyecta las sombras de los apóstoles contra el respaldo del banco corrido, bien a la izquierda o a la derecha.

Los muros de la sala capitular de la catedral de Toledo están decorados por entero, exceptuando la zona que ocupan los asientos del cabildo. Por encima de ellos encontramos las pinturas murales de los arzobispos de Toledo desde san Eugenio hasta el cardenal Cisneros ${ }^{41}$, articuladas de la misma manera que la parte superior, pero en vez de columnas, la separación se hace mediante cortos pilares de fuste rehundido con decoración a candelieri, y salvo en los muros cortos, todos mantienen la división dictada por los frescos superiores. El muro oriental, donde empieza y termina la serie, está protagonizado por la silla arzobispal, enmarcada por pilares fingidos, y a los lados seis arzobispos en cada uno de los tramos. En el muro occidental, donde el Juicio Final no admite separaciones de ningún tipo, en la serie de retratos se añaden dos pilares que enmarcan la parte superior de la puerta de acceso. Las setenta y dos figuras de tres cuartos de los arzobispos están dispuestas detrás de un antepecho, vestidos con capa pluvial y mitra, no se pueden considerar retratos porque la mayoría de ellos fueron realizados sin conocer al retratado. La expresión no se encuentra en los rostros sino en los gestos de las manos, unas sostienen libros, otras cruces, algunas se apoyan sobre la teja cardenalicia, etc.; los rostros se vuelven de perfil, o tres cuartos a un lado y otro, miran al compañero o leen en su libro. La perspectiva se estudia individualmente en cada uno de los prelados mediante detalles como la manera de apoyarse en el antepecho, de plegarse la capa, en los escorzos de las manos o de las tejas. El tratamiento del volumen se acentúa con la luz frontal que se entremete en los pliegues del alba y las dobleces de la capa pluvial.

Juan de Borgoña estudia, observa y plantea minuciosamente cada composición, quiere conseguir que el espacio pictórico fingido sea continuación del real, no importa que sean paisajes, interiores, o combinación de distintos ámbitos, introduce al espectador en su discurso de juego de planos y escalonamiento proporcional hacia un fondo lejano, en una pausada disminución de volúmenes de variada naturaleza. Amplía el espacio pictórico mediante una visión frontal escorzada unilateral, con un punto de fuga excéntrico, que la mayoría de las veces oscila en un pequeño margen, pero muestra también su dominio de la perspectiva centralizada en algunas composiciones. Tiene en cuenta en todo momento el lugar donde se encuentra la pintura, dónde estará el espectador, y no duda en descender el punto de fuga lo que haga falta para conseguir una visión óptima, inclina los techos, para ser vistos desde abajo, analiza cada elemento,

${ }^{41}$ A partir del cardenal Cisneros los retratos son al óleo y sobre tela. 
para que pueda resultar lo más convincente posible. Contrapesa los espacios opacos y abiertos para equilibrar la composición, donde a veces predomina la recta, la curva, la horizontal, la vertical o la diagonal. Le gusta abrir espacios dentro de otros espacios, o exteriores dentro de interiores. Mediante la luz moldea el volumen, no sólo de los seres vivos, también de cada elemento arquitectónico, a veces rehundidos para introducir algún relieve, normalmente vegetal. La iluminación le sirve para reafirmar el sentido de profundidad con lugares ensombrecidos o dorados refulgentes. En las zonas más alejadas la atmósfera se densifica creando una nebulosa que difumina los contornos. Podemos decir que la perspectiva lineal es dominada por Juan de Borgoña, la aplica bajo su criterio para acercarse lo más posible a la naturaleza, no superarla de manera científica, pero sí emularla, se podría hablar de perspectiva aérea ${ }^{42}$.

La opinión generalizada apoya una formación italiana de Juan de Borgoña antes de su llegada a Toledo, y un segundo viaje anterior a los encargos de Ávila y de la sala capitular. Ghirlandaio ha sido el nombre más barajado y se ha apuntado la posibilidad de una relación de maestro y pupilo entre el pintor italiano y Juan de Borgoña, comparando los frescos de la sala capitular de la catedral de Toledo con los de Ghirlandaio en el coro de santa María Novella. Sin entrar a debatir en el tratamiento de las figuras de uno y otro artista, atendiendo únicamente a la disposición del espacio y al estudio de la perspectiva, Ghirlandaio centraliza todas sus composiciones individualmente y crea espacios más complejos, repletos de detalles y figuras, no se puede dudar del mismo gusto por las decoraciones vegetales en las arquitecturas renacentistas, la apertura a otras estancias o al exterior con árboles y motivos naturalistas, y la disposición de los frescos separados por un pilar central en Ghirlandaio, pero incomparable con lo que hace Borgoña, no evita la brusquedad en la separación de las escenas colaterales. La concepción del espacio de uno y otro pintor es totalmente diferente. Revisando el catálogo de obras de los nombres de pintores italianos que se han barajado en relación con Juan de Borgoña, no encontramos la visión frontal escorzada unilateral tan característica en su obra. El apellido de Juan de Borgoña ha hecho pensar en una primera enseñanza nórdica ${ }^{43}$, como naturalista observa la naturaleza y la continúa en su pintura, incluye ciertas anécdotas y adopta una pincelada menuda y cuidadosa para pintar con todo detalle, sus soluciones acaban siendo empíricas ${ }^{44}$. Pero su manera de componer, la perspectiva decelerada en un punto de fuga bajo que obliga a ver las pinturas a cierta distancia, no es la característica de las tablas flamencas del siglo $\mathrm{Xv}^{45}$. En la Península Ibérica no se pueden encontrar antecedentes para el tratamiento del

${ }^{42}$ A estas alturas del discurso sería conveniente comparar esta obra capital en Juan de Borgoña con otras de su catálogo, pero por problemas de espacio se puede resumir diciendo que en el retablo de la Epifanía de la catedral de Toledo, obra anterior, se nota una gran diferencia en el tratamiento del espacio. Esto no ocurre con las tablas atribuidas a Juan de Borgoña en el retablo mayor de la catedral de Ávila, donde se repiten elementos, soluciones arquitectónicas, puntos de vista y profundos espacios. No se puede decir lo mismo de la pintura mural en la capilla Mozárabe de la catedral primada, con la representación del acontecimiento histórico tenido lugar en Orán, cuyo protagonista era el comitente, el cardenal Cisneros, como mero documento histórico, las casas de la ciudad se apiñan en la ladera de una montaña y sus murallas se ven invadidas por gigantes que no podrían caber por sus puertas (F. MARías FranCo, loc. cit. nota 22, p. 205, justifica las aberraciones de estas pinturas por «razones de género narrativo»), si Juan de Borgoña hubiera atendido a la proporción de las figuras no podía haber representado más que una pequeña parte, y si los soldados adoptaran el tamaño dictado por las casas se convertirían en figuritas irreconocibles, el fin, era narrativo y no estético.

${ }^{43}$ Nos parece muy interesante señalar en este punto la opinión de Fernando MARías, loc. cit. nota 22, p. 207, de la confusión al calificar de italianos algunos rasgos adoptados en la pintura española provenientes del gótico flamenco, el arte italiano muchas veces simplemente pone al día esos rasgos.

${ }^{44} \mathrm{~S}$. Alpers, El arte de describir: el arte holandés en el siglo XVII, 1. a ed. en inglés 1983, Madrid, 1987, describe la diferencia entre la pintura nórdica y la italiana con respecto al tratamiento de la naturaleza, y el resultado es una pintura descriptiva holandesa y narrativa italiana, aparte de la prioridad del espectador, la falta de un marco previo y los contrastes de escala en el norte. Características que podemos encontrar en Juan de Borgoña, de la misma manera que las italianas. H. DAmisch, loc. cit. nota 30, p. 53, hace prevalecer la maestría en la perspectiva de los Países Bajos sobre la italiana.

45 E. PANOFSKY, La perspectiva como forma simbólica, 1. a ed. 1927, Barcelona, 1973, pp. 41, 45 y 52-53, establece las diferencias entre el Norte y el Sur en la representación del espacio, señala el empirismo y el subjetivismo nórdicos con una posición excéntrica del punto de vista, y la teorización matemática y el objetivismo italianos negando la diagonal. 
espacio en Juan de Borgoña ${ }^{46}$. El mismo Ceán denuncia la falta de estudio en la armonía de los grupos y la degradación de la perspectiva en la pintura española del siglo $\mathrm{XV}^{47}$. Juan de Borgoña podría estarse anticipando a las demandas de los primeros tratadistas que hacen alguna referencia a la perspectiva ${ }^{48}$.

Pensamos que podría ser un pintor español con posible estancia en Italia en el que Juan de Borgoña pudiera fijarse para sus composiciones y soluciones perspectívicas, para apoyar esta teoría nos remitimos a la primera noticia de Juan de Borgoña en Toledo, referente a la pintura del claustro de la catedral de Toledo, obra donde trabaja Pedro Berruguete como pintor principal. Ya hemos visto cómo a medida que se avanzaba en los estudios sobre Juan de Borgoña, aparecía más a menudo el nombre de Pedro Berruguete en relación con la pintura del autor de los frescos de la sala capitular ${ }^{49}$. La prueba de esta estrecha relación y la importancia de Berruguete en el estilo de Juan de Borgoña, la tendríamos en esos frescos desaparecidos del claustro de la catedral de Toledo, sin ellos debemos conformarnos con los datos que van apareciendo en el estudio de sus obras.

Juan de Borgoña y Pedro Berruguete utilizan elementos comunes, en realidad responden algunos al gusto español, pero es en ellos dos donde los encontramos. Nos estamos refiriendo a los techos de alfarje dorados ${ }^{50}$, al enmarque de las composiciones (con elementos góticos en Berruguete), a la utilización de fustes de mármol italiano pulido, a la decoración vegetal, y, lo más importante, al tratamiento de la perspectiva con punto de fuga excéntrico en una visión frontal escorzada unilateral ${ }^{51}$. En la catedral de Ávila ambos pintores utilizan este mismo tipo de composición espacial, y Pedro Berruguete en el monasterio de santo Tomás o en las pinturas murales del exterior de la entrada a la capilla de san Pedro de la catedral de Toledo ${ }^{52}$. En los bancos de los retablos de santa Eulalia de Paredes de Nava y de santo Tomás de Ávila, Berruguete retrata a los monarcas de Judá y a evangelistas y padres de la Iglesia en disposiciones similares a las de los arzobispos de la sala capitular, vistos de tres cuartos delante de un antepecho donde apoyan un libro, una flauta o simplemente parte de su capa, pero más llamativa es la comparación de los prelados con el tratamiento de los padres de la Iglesia de colección particular atribuidos a Pedro Berruguete reproducidos en color por Silva ${ }^{53}$. Pedro Berru-

46 P. Martínez-Burgo García, «La perspectiva y el paisaje en la pintura española del siglo xvi», Goya, n 185,1985 , pp. 282-289. M. A. RAQuejo GRADo, «El donante en la pintura española del siglo Xvi: su ubicación en el espacio ficticio», Goya, $\mathrm{n}^{\circ} 164-165,1981, \mathrm{pp} .76-87$.

47 J. A. Ceán Bermúdez, loc. cit. nota 3, I, p. XLI. R. L. KAGAN, «La Toledo del Greco» en El Greco de Toledo [Exposición], Madrid, 1982, p. 61, recoge las palabras de fray Miguel de Medina, 1570, referentes a la pintura «que en todas sus especies y maneras depende de la perspectiva». Miguel Herrero GARCíA, Contribución de la literatura a la Historia del Arte, Madrid, 1943, p. 177, reproduce un texto correspondiente a Alonso de la Cruz, Discursos Evangélicos, 1599, p. 569, con el que se puede ver cómo a finales del siglo xvi aún se delataban las carencias en el conocimiento de la perspectiva en España.

${ }^{48}$ F. DE Holanda, De la pintura antigua, en portugués 1548, versión castellana de M. Denis 1563, Madrid, 1921, pp. 113-120, es el primero que dedica tres breves capítulos a la perspectiva, con los principios vitruvianos de «ichonografía, ortografía y sciografía», y albertianos de la pirámide visual. J. EMILIo BuRUCúA, «Arte difícil y esquiva. Uso y significado de la perspectiva en España, Portugal y las colonias iberoamericanas (siglos XVI-XVIII)», Cuadernos de Historia de España, LXXI, 1989, pp. 131-186; LXXII, 1990, pp. 179-280; 1991, LXXIII, pp. 173-290. L. CABEZAS GELABERT, «La «Perspectiva angular» y la introducción de la perspectiva artística en la España del siglo XVI», D'Art, n 15, 1989, pp. 167-179.

49 D. Angulo ÍñIguez, 1954, loc. cit. nota 15, p. 12. Ídem, 1955, loc. cit. nota 15, p. 117. A. Condorelli, loc. cit. nota 17, p. 49. R. Buendía, loc. cit. nota 19, p. 208.

50 D. Angulo, 1954, idem, p. 17.

${ }^{51}$ P. Silva, «Notas sobre Pedro Berruguete y el retablo mayor de la catedral de Ávila», Anales de Historia del Arte de la Universidad Complutense, I, n ${ }^{\circ} 1,1989$, p. 111 (nota 24), hace mención a cómo Pedro Berruguete en la representación del espacio muestra mayor influencia nórdica al utilizar el punto de vista excéntrico.

52 Precisamente también existiría cierta similitud en la manera de tratar el techo con casetones en esta pintura de la entrada a la capilla de san Pedro y en el Nacimiento de la Virgen de la sala capitular.

53 P. Silva, Pedro Berruguete, Salamanca, 1998, p. 355, láms 92 y 93. La comparación con estas dos tablas atribuidas a Pedro Berruguete podría extenderse a otras obras de Juan de Borgoña, como en el caso concreto de las figuras de los padres de la Iglesia en el banco del retablo de la capilla de la Trinidad de la catedral de Toledo, que además están empareja- 
guete abre unos espacios dentro de otros como en la Decapitación del Bautista de la iglesia de santa María del Campo (Burgos) o en la Anunciación de la Cartuja de Miraflores.

Pilar Silva, en el último estudio publicado sobre Pedro Berruguete, defiende la salida de Castilla del pintor castellano con destino a Italia, entre 1472 y 1473 , con el fin de perfeccionar su arte $^{54}$, se decanta por una primera estancia en Roma donde contactaría con la pintura de Melozzo da Forlì de punto de vista de sotto in su $^{55}$, en 1474 llegaría a Urbino, donde podría haber coincidido con Piero della Francesca ${ }^{56}$. La vuelta a Toledo la justifica con cuestiones privadas, pero también por la necesidad de artistas para la catedral y su relación con el cardenal Mendoza, quien debió de interceder para su trabajo en el sagrario de $1483^{57}$, su relación con la catedral se corta a raíz de la muerte de Mendoza en $1495^{58}$. Justifica la disminución de calidad de la pintura de Berruguete al llegar a Castilla por amoldarse al gusto del comitente castellano y porque las empresas son mayores, mientras que en Italia se encargó de pinturas en pequeño formato ${ }^{59}$. Silva al hacer referencia al tratamiento del espacio en la pintura de Pedro Berruguete, habla de empirismo porque tiene conocimiento de la perspectiva lineal pero la aplica de manera sui generis, un punto de vista excéntrico y bajo, con intercomunicación de espacios ${ }^{60}$.

Piero della Francesca escribe su tratado De Prospectiva pingendi hacia 1470, basado en el tratado de Alberti, si realmente Berruguete estuvo en Urbino desde 1473, debió de coincidir en las fechas en que se gestaba el tratado y los estudios sobre el espacio bullían. Cabría la posibilidad de establecer una estancia de Juan de Borgoña en Urbino en fechas cercanas a la década de los ochenta, coincidiendo con Pedro Berruguete y las ideas de Piero della Francesca ${ }^{61}$. Las similitudes en la concepción del espacio entre Borgoña y Berruguete se justificarían mediante la existencia de un núcleo común de aprendizaje y teorización, cada uno, después, asimilaría a su manera lo aprehendido ${ }^{62}$. En Castilla, tanto en Berruguete como en Borgoña, se producirá un descenso de la calidad, fruto de las exigencias del gusto ibérico y del ambiente social y artístico tan diferente a la condición del artista en Italia.

La llegada de Juan de Borgoña a Toledo y su relación con la catedral podría también estar

dos entre ellos de igual manera; o también en dos tablas del Bowes Museum en Inglaterra de esto mismo tema, y aunque se prescinde de la partición por columnas, los santos en sí harían dudar en la atribución a Juan de Borgoña o a Pedro Berruguete, con la idea generalizada a favor del primero.

54 Ídem, p. 70.

55 Ídem, pp. 78 y 109.

56 Ídem, p. 81.

57 Ídem, pp. 120-122.

58 Ídem, p. 58, no relaciona esta desvinculación de la catedral por la desaparición del cardenal Mendoza. Sin embargo parecería lo más lógico, al producirse un cambio en el gusto con la aparición del cardenal Cisneros.

59 Ídem, pp. 39, 116-117.

60 Ídem, pp. 167-170 y 209-210. A. Ávila, loc. cit. nota 23, p. 544, pone como ejemplo de excentricidad del punto de fuga la Decapitación del Bautista de santa María del Campo.

${ }_{61}$ R. Buendía, loc. cit. nota 19, p. 208, al comparar el trono de la Virgen de la Imposición de la casulla a san Ildefonso del Meadows Museum de Dallas, atribuida a Juan de Borgoña, con el de la Fortaleza de Botticelli o de las otras Virtudes realizadas para el Gremio de la Mercadería de Florencia (1470), para justificar la influencia florentina en esta obra de Juan de Borgoña, surge el nombre de Piero della Francesca y un posible viaje a Urbino de aquél con la coincidencia con Pedro Berruguete, incluso R. Buendía se atreve a comparar la Imposición de Dallas con el retrato de Federico de Montefeltro y su hijo escuchando la lección de un humanista, realizado para el palacio Gubbio, lanzando la posibilidad de un único autor para ambas pinturas. La comparación del trono de la Imposición de Dallas se extendería también a Pedro Berruguete con los tronos de las Artes liberales realizadas para la decoración del studiolo del mismo palacio Gubbio de Urbino. Nosotros en este punto observamos que el trono de la Música de estas últimas es el más cercano al de la Virgen. Y queremos añadir algunas coincidencias entre las pinturas de la sala capitular y la tabla de Dallas, por ejemplo, las santas del lado derecho de ésta con las de la Imposición del cabildo, donde también el pavimento es similar como en la Purificación, con los niños de la Presentación de la Virgen, con los capiteles y con otros elementos arquitectónicos, concretamente el juego de los sustentantes de la Dormición.

${ }^{62}$ E. Bertaux, loc. cit. nota 9, p. 922, se interroga sobre el conocimiento de la perspectiva italiana en Juan de Borgoña en Florencia o en Castilla, y cómo de él lo recibiría Berrruguete. R. BuEndía, loc. cit. nota 19, p. 208, relaciona a Juan de Borgoña con Pedro Berruguete en Urbino. 
justificada por su relación con Berruguete, así como la elección de ambos, en diferentes momentos, para el retablo de la catedral de Ávila. La época álgida de Berruguete en Toledo coincide con el arzobispado de Mendoza, mientras que Borgoña, será el pintor del cardenal Cisneros. Borgoña parece seguir los pasos de Berruguete con unos años de diferencia.

Queremos con este estudio concluir apoyando la idea de una estancia italiana de Juan de Borgoña, indudable, por infinidad de elementos que únicamente pudo extraer de allí ${ }^{63}$. Pero no desdeñamos, en absoluto, su relación con el arte nórdico, porque su visión de la naturaleza y del arte, más abierta y empírica, no es italiana ${ }^{64}$. Ambas corrientes se mezclan en un estilo que será eminentemente castellano, e irrumpirá con gran fuerza creando un influjo imborrable a lo largo de los años.

\footnotetext{
${ }^{63}$ Aprovechamos la alusión a la estancia italiana de Juan de Borgoña para hacer referencia a un importante encargo en su vida artística, la pintura mural en la biblioteca de la catedral de Toledo, empezada el 16 de febrero de 1516 (F. Pérez SEDANo, loc. cit. nota 1, pp. 44 y 138) y terminada de pagar el 22 de octubre de 1519 (F. Pérez SEDANo, loc. cit. nota 1, pp. 42 y 138), obra no conservada pero en la que no se puede evitar pensar en Italia, y en las decoraciones urbinescas o romanas (F. MARíAS, loc. cit. nota 22, pp. 204-205, hace alusiones romanas al describir las pinturas de la antesala capitular, concretamente la compara con la Sala Greca vaticana, la Casa de los Caballeros de Rodas y alguno de los salones de Inocencio VIII en el Belvedere, al referirse a la propia sala capitular la compara con la Capilla Sixtina, y en relación a la biblioteca dice que podría estar emulando a la de Sixto IV en el Vaticano). La reconstrucción de este recinto se complica por los cambios que ha sufrido. Blas OrTiz, La Catedral de Toledo 1549. Según el Dr. Blas Ortiz: Descripción Graphica y Elegantissima de la S. Iglesia de Toledo, Madrid, 1999, p. 262, describe la catedral de Toledo de los años finales de la primera mitad del siglo xvI, y ubica la antigua librería subiendo por una escalera situada en un aula a la derecha de la entrada principal al claustro. S. R. PARRo (loc. cit. nota 5, pp. 681-688) la sitúa en el mismo lugar, encima de la que fue sala capitular de verano, en el ala este del claustro, con acceso subiendo la escalera que se encuentra en la antesala, fue construida antes que el claustro en tiempos del arzobispo Tenorio, y aunque sigue ocupando el mismo sitio fue cambiando con Mendoza, Cisneros y Lorenzana, con este último ocupaba todo el lado este del claustro con cuatro ventanas, tal y como la vio PARRo. L. MORENO NiETo, Diccionario enciclopédico de Toledo y su provincia, Toledo, 1974, p. 90, concreta y dice que el segundo cuerpo de galerías del claustro lo construyó el cardenal Cisneros como corredor de la biblioteca, salón de siete bóvedas. R. GonZÁLVEZ Ruiz, «Blas Ortiz y su mundo» en La Catedral de Toledo 1549. Según el Dr. Blas Ortiz: Descripción Graphica y Elegantissima de la S. Iglesia de Toledo, Madrid, 1999, p. 56, añade que el cardenal Tavera quería ser enterrado en la catedral y funda donde ahora está la librería una capilla. Con estas citas podemos resumir diciendo que la biblioteca se situaba en la galería superior del lado este del claustro, que ocupaba toda su longitud con las siete bóvedas, y construida antes del arzobispado del cardenal Cisneros fue restaurada bajo su patrocinio, pero ha sufrido continuos cambios posteriores. Aún así podemos imaginarnos el imponente salón que Juan de Borgoña tuvo que decorar con pinturas murales, ya había participado en otras decoraciones de este tipo en la catedral de Toledo, siempre había desarrollado temas sacros, tanto en el claustro como en la sala capitular, posiblemente en la biblioteca continuara en la misma línea al seguir siendo un recinto sagrado, aunque también pudo recordar lo que había visto en Italia y adoptar temas profanos, sin que podamos olvidar que una biblioteca tiene las paredes cubiertas de armarios y la decoración tendría que limitarse al techo y poco más. Aún así ocupó aparentemente más tiempo que para la sala capitular, ocupado en ella probablemente desde los primeros pagos del 26 de septiembre de 1509 hasta los últimos en noviembre de 1511, con algunas interrupciones para realizar pinturas artesanales para la catedral y el retablo de la capilla Mozárabe con otros pintores; en la librería parece que trabaja desde el 16 de febrero de 1516 hasta los últimos pagos del 22 de octubre de 1519 , en principio le dedicó más tiempo, aunque se vio interrumpido para realizar el retablo de la iglesia parroquial de Camarena (Toledo) y los reparos del de san Eugenio de la catedral.

${ }^{64}$ Nuestra teoría de que en Juan de Borgoña hay que valorar más que hasta este momento su formación nórdica se ha visto reforzada últimamente por algunos detalles, como la conversación sostenida con Paloma Renard, restauradora del Instituto del Patrimonio Histórico español, y concretamente de la tabla atribuida a Juan de Borgoña con el tema de la Cruz en el Calvario de la Universidad Complutense de Madrid, quien nos contaba cómo Juan de Borgoña trabaja sobre tabla de pino gruesa, con importante capa de imprimación, es decir, a la manera eminentemente castellana, divide la composición con una cruz en aspa, pinta con una técnica mixta de huevo y aceite, utiliza veladuras y consigue un grado importante de detallismo, características todas propias de un pintor formado a la flamenca. En el catálogo de la Exposición de Las tablas flamencas en la Ruta Jacobea, San Sebastián, 1999, se comentan dos tablas atribuidas a Juan de Borgoña: el ático del retablo de la Epifanía de la iglesia parroquial de Briones (Logroño), comentada por E. BERMEJo (pp. 296-299), quien destaca las características nórdicas en el paisaje del supuesto autor del retablo (p. 298); y La Última Cena de Colección Particular comentada por I. MATEO GómEz (pp. 326-327), quien destaca el detallismo, el gusto por la anécdota y las calidades, características nórdicas, de su autor (p. 326). Hasta ahora se ha hablado siempre de un aprendizaje italiano desdeñando el nórdico, si en Berruguete, para SiLvA, su viaje a Italia es de perfeccionamiento, probablemente para Juan de Borgoña también, en el que cada vez más se puede ver a un pintor flamenco con profundo conocimiento de lo que se venía haciendo en Italia, pero esto no significa una infravaloración de su pintura. En España para estos años de principios del Renacimiento hablar de flamenquismo es hablar de poca calidad, mientras que el término italinismo es engrandecedor, en Juan de Borgoña la mezcla de ambos da como resultado una pintura de élite.
} 